\title{
A Practical Application of FRBR for Organizing Information in Digital Environments ${ }^{\dagger}$
}

\author{
Yunseon Choi \\ Graduate School of Library and Information Science, University of Illinois \\ at Urbana-Champaign, 501 E. Daniel Street, MC-493, Champaign, IL 61820-6211, USA, \\ $<y$ choi10@illinois.edu>
}

Yunseon Choi received her Ph.D. in Library and information Science from the University of Illinois at Urbana-Champaign. She will join the faculty of the Information and Library Science Department at Southern Connecticut State University in August 2012. Her research interests are diverse aspects of information organization including metadata, ontologies, folksonomy, information seeking behaviors, and information architecture. She is particularly interested in social media and information technology in the context of information organization and access in digital environments. Her research focus in information organization is on bringing the user perspective into the organization and retrieval of digital information.

Choi, Yunseon. A Practical Application of FRBR for Organizing Information in Digital Environ-

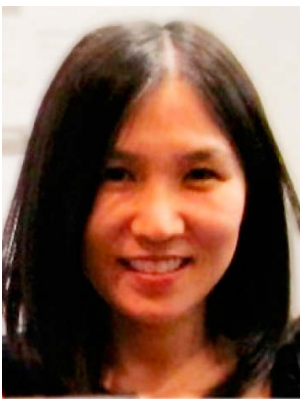
ments. Knowledge Organization. 39(4), 233-254. 69 references.

\begin{abstract}
This study employs the FRBR (Functional Requirements for Bibliographic Records) conceptual model to provide in-depth investigation on the characteristics of social tags by analyzing the bibliographic attributes of tags that are not limited to subject properties. FRBR describes four different levels of entities (i.e., Work, Expression, Manifestation, and Item), which provide a distinguishing understanding of each entity in the bibliographic universe. In this research, since the scope of data analysis focuses on tags assigned to web documents, consideration on Manifestation and Item has been excluded. Accordingly, only the attributes of Work and Expression entity were investigated in order to map the attributes of tags to attributes defined in those entities. The content analysis on tag attributes was conducted on a total of 113 web documents regarding 11 attribute categories defined by FRBR. The findings identified essential bibliographic attributes of tags and tagging behaviors by subject. The findings showed that concerning specific subject areas, taggers exhibited different tagging behaviors representing distinctive features and tendencies. These results have led to the conclusion that there should be an increased awareness of diverse user needs by subject in terms of the practical implications of metadata generation.
\end{abstract}

$\dagger$ This paper is derived from the author's doctoral dissertation "Usefulness of Social Tagging in Organizing and Providing Access to the Web: An Analysis of Indexing Consistency and Quality.” The author is deeply grateful to her dissertation committee-Dr. Linda C. Smith chairperson, Drs. Allen Renear, Miles Efron and John Unsworth.

Received 25 February 2012; Revised 18 April 2012; Accepted 30 April 2012

\subsection{Introduction}

This study is part of a larger research project that points out major challenging problems with current Knowledge Organization (KO) systems for web resources, such as subject gateways or web directories: 1) the current systems use traditional knowledge or- ganization systems based on controlled vocabulary, which are not very well suited to web resources (Golub 2006; Nowick and Mering 2003; Macgregor and McCulloch 2006), and 2) information is organized by professionals not by users, which means it does not reflect intuitively and instantaneously expressed current user needs (Golub 2006). In order to 
explore users' needs, we examined social tags, which are user-generated uncontrolled vocabulary. As investment in professionally-developed subject gateways and web directories diminishes (support for both BUBL and Intute, examined in this study, is being discontinued), understanding characteristics of social tagging becomes even more critical.

Social tagging has received significant attention since it helps organize contents by collaborative and user-generated tags. Users' tags reflect their language because social tagging allows users to add their own tags based on their interests. Several researchers have discussed the impact of tagging on retrieval performance on the web (Bao et al. 2007; Choi 2009; Choy and Lui 2006; Golder and Huberman 2006; Heymann, Koutrika and Garcia-Molina 2008; Kipp and Campbell 2010; Sen et al. 2006; Yanbe et al. 2006). Choy and Lui (2006) have applied the statistical tool of Latent Semantic Analysis (LSA) to the evaluation of tag similarity by examining pairs of tags of singular and plural forms, and concluded that collaborative tagging has a great impact on retrieval. Yanbe et al. (2006) have explored an approach to enhancing search by proposing combining a link-based ranking metric with social tagging data and investigated the utility of social bookmarking systems. Bao et al. (2007) have explored the use of social annotations to improve web search and stated that social annotations could be useful for web search by focusing on two aspects: similarity ranking (between a query and a web page) and static ranking. On the other hand, Choi (2009) has analyzed tags in order to improve web searching by bringing a more accurate user's perspective into the design of web navigation. In her research, Choi (2009) has provided a new angle for understanding social tags by considering them as "facets.” Kipp and Campbell (2010) also have conducted a study examining whether tags would be useful for information retrieval by limiting the scope of information to scholarly documents such as academic articles at CiteULike and PubMed online journal database. Several studies have explored tags in the context of indexing languages by comparing tags with controlled vocabularies (Good and Tennis 2009; Kipp 2005). On the other hand, Good, Kawas and Wilkinson (2007) have proposed the semantic social tagging application that helps semantic annotations of data in biomedical literatures. Additionally, there have been studies reporting the other aspects of tags such as task and emotion (Kipp 2007a; Neal 2010; Tonkin et al. 2007). There have been also studies on the comparison of users' tags and professionals or intermedi- ary indexers' keywords (Kipp 2007b; Choi 2010a, b and c). Kipp (2007b) especially has examined healthrelated information tags assigned in PubMed articles. She compared tags from users and descriptors from intermediary indexers. Choi (2010a) has focused on bridging the gap of insufficiency of studies on vocabulary analysis by comparing user-generated tags with professionally-generated index terms regarding web resources. The comparison of users' tags and indexers' keywords has been promoted by analyzing indexing consistency (Choi 2010b and c). Furthermore, several researchers have discussed the usefulness of social tagging for cataloging and classification by examining the linguistic aspects of user vocabulary (Makani and Spiteri 2010; Spiteri 2007). However, further research is needed to qualitatively as well as quantitatively investigate social tagging and to systematically verify its quality and benefit, which is the first necessary step to utilize social tagging in digital information organization.

To address identified problems with current web organization systems, we aim to investigate whether user-generated tags through social tagging could be used to enhance access to web resources and provide additional access points beyond professionallygenerated ones, and whether we could verify the usefulness of social tagging to obtain benefit from it. In this paper, we particularly investigate tag attributes and tagging behaviors. To provide in-depth investigation on the characteristics of tags, we analyze the bibliographic attributes of tags that are not limited to subject properties. Thus, the following research questions are answered: What are features and patterns of social tagging in describing a web document? Do tags have other bibliographic attributes beyond describing subjects or topics of a document?

The process of identifying bibliographic attributes of tags was based on the Functional Requirements for Bibliographic Records (FRBR) model. Because the attributes defined in the FRBR model were derived from "a logical analysis of the data that are typically reflected in bibliographic records" (IFLA 1998), the model supports a more systematic and meticulous analysis of the attributes of tags.

\subsection{Background}

\subsection{Subject gateways as organizing tools for the web}

A growing number of web resources have required new tools for organizing and providing more effective access to the web. Subject gateways and web directo- 
ries are such tools for internet resource discovery. The subject gateways emerged in response to the challenge of "resource discovery" in a rapidly developing Internet environment in the early and mid1990s. The term "subject gateway" was commonly used in the UK Electronic Libraries Programme (eLib) (Dempsey 2000). eLib was a JISC-funded programme of projects in 1996 (initially £15m over 3 years but later extended to 2001). Projects included Digitisation, Electronic Journals, Electronic Document Delivery and On-Demand Publishing (Hiom 2006). Under the eLib project, Internet subject gateways were established to deal with Internet searching problems, such as finding good quality and relevant resources (Burton and Mackie 1999).

Subject gateways can be enumerated by the subject categories they cover (University of Kent 2009). For instance, Social Care Online (http://www.scie-social careonline.org.uk/) (professional development support portal), SocioSite (http://www.sociosite.net/) (the University of Amsterdam's social science information system), and SWAP (Social Policy and Social Work) (http://www.swap.ac.uk/) (subject portal providing resources to support teachers and lecturers in this subject) are subject gateways that provide resources in social science subjects. For a psychology subject area, there are CogNet (http://cognet.mit. edu/) (MIT portal for the brain sciences), Psych Net.UK (http://www.psychnet-uk.com/) (a comprehensive UK gateway to psychology information) and so on. Doctors.net.uk (http://www.doctors.net.uk/) (Peer led internet resource for UK doctors) and HON (Health On the Net) (http://www.hon.ch/) (international Swiss initiative to make quality guidance about medical treatments and health information available to patients and public) are examples for health and medicine subjects. As examples of subject gateways covering various subject areas, there are BUBL Link (http://www.bubl.ac.uk/index.html) and Intute (http://www.intute.ac.uk/). BUBL describes itself as 'Free User-Friendly Access to selected internet resources covering all subject areas, with a special focus on Library and Information Science' (Wikipedia). Intute is a free web service aimed at students, teachers, and researchers in UK further education and higher education (Wikipedia). BUBL offers broad categorization of subjects based on the Derwey Decimal Classification (DDC) scheme (BUBL Link Home). For each subject, subject specialists like librarians work on the maintenance and development of subject categories. However, it has been noted that BUBL is no longer being updated as of April 2011 (BUBL Link Home), as support for BUBL is being discontinued. The selection for inclusion of resources within the Intute collection considers the quality, relevance and provenance of resources (Abbott 2009). It is reported that Intute mainly uses the Universal Decimal Classification (UDC) and DDC for classification and has adapted them for in-house use. Intute subject specialists collaboratively catalog web documents. However, recently it has been noted that Intute is closing after July 2011 (Intute Home), as support for Intute is being discontinued.

\subsection{Challenges of controlled vocabulary for the web}

For effective indexing and retrieval, the indexing process needs to be controlled by using a so-called controlled vocabulary (Lancaster 1972). Since the 19th century, controlled vocabularies have been developed and used for subject indexing. Lancaster identifies three major manifestations of controlled vocabulary: bibliographic classification schemes, subject heading lists and thesauri.

Controlled vocabulary has many advantages. One of the major advantages of controlled vocabulary is that it can increase the effectiveness of retrieval by providing unambiguous, standard search terms with a control of polysemy, synonymy, and homonymy of the natural language (Golub 2006; Muddamalle 1998). Another benefit from controlled vocabulary is that it improves the matching process with its systematic hierarchies of concepts featuring a variety of relationships like "broader term," "narrower term," "related term," or "see" and "see also" (Golub 2006; Olson and Boll 2001). However, as there are more and more resources available on the web, existing controlled vocabularies have been challenged in their ability to index the range of digital web resources. The challenges of controlled vocabulary for the web can be summarized as follows.

One of the major challenges of controlled vocabulary in the digital environment is the slowness of revision. Indexing web content requires an updated thesaurus, but usually subjects are rapidly evolving with new terminology, so it is hard to always keep up-todate vocabulary (Muddamalle 1998). Golub (2006) also addresses "improved currency" and "hospitality for new topics" as new roles which controlled vocabularies need to take. The other problem is that the construction of controlled vocabularies and indexing are labor-intensive and expensive (Fidel 1991; Macgregor and McCulloch 2006). The process of indexing is conducted by professional efforts requiring ex- 
pert knowledge (Olson and Boll 2001). Another obstacle of controlled vocabulary is that it has been developed with a focus on physical and traditional library collections. Traditionally, controlled subject headings have been employed for indexing physical resources, so they need to be flexible or expandable in order to encompass web resources (Golub 2006; Nowick and Mering 2003; Macgregor and McCulloch 2006). For instance, Library of Congress Subject Headings $(L C S H)$ is designed to describe monographs and serials, so it might not be specific enough for describing web resources (Nowick and Mering 2003). Furthermore, Nicholson et al. (2001) have discussed the problems with controlled vocabularies in indexing for describing online collections by identifying that "they have a lack of, or excessive, specificity in the subject areas." Last but not least, controlled vocabulary should be comfortable for users to use, and it should be able to meet the users' interests and their needs (Golub 2006). Golub mentions "intelligibility, intuitiveness, and transparency" as new challenges for controlled vocabulary.

Using free-text or natural language terms is one alternative to resolve identified problems with controlled vocabulary. Advantages of free-text terms are that they require only non-professional knowledge for searching techniques for users and reflect up-todate vocabulary (Dubois 1987). Social tagging data is one example of natural language terms, that is, uncontrolled vocabulary assigned by users. Social tagging is a promising way to complement the disadvantages of professional indexing because it is low-cost since a great number of users from everywhere contribute to the creation of tags. Thus, users' tags might be alternate terms with additional entry points of retrieval that are not easily attained using controlled vocabularies (Hayman 2007; Maltby 1975; Quintarelli 2005). Tags are generally much more current than controlled vocabulary because they are constructed in the process of sensemaking, in that users share their experiences in subject terms reflecting their interests in various communities (Smith 2007). Unlike hierarchical structures (broader and narrower terms) of controlled vocabularies, folksonomies are inherently flat, which allows great flexibility in indexing terms. Moreover, as investment in professionally-developed subject gateways and web directories diminishes (support for both BUBL and Intute, examined in this study, is being discontinued), understanding characteristics of social tagging becomes even more critical. In the next section, more details about social tagging and relevant issues will be described.

\subsection{Social tagging for organizing the web}

Social tagging is described as "user-generated keywords" (Trant 2009). Because tags indicate users' perspectives and descriptions in indexing resources, they have been suggested as a means to improve search and retrieval of resources on the web. The term "social tagging" is frequently associated with the term "folksonomy," which was coined by Thomas Vander Wal from 'folk' and 'taxonomy' (Neal 2007). Folksonomy consists of three elements: users, resources to be described, and tags for describing resources (Vander Wal 2005). Vander Wal (2007) describes "folksonomy" as "user-created bottom-up categorical structure development with an emergent thesaurus." Quintarelli (2005) defines folksonomy as "user-generated classification, emerging through bottom-up consensus." Examples of folksonomy sites include Flickr, Delicious, and LibraryThing. Social tagging has been popularized by tagging sites such as Flickr, Technorati and Delicious. Delicious is one of the most popular social bookmarking services, allowing users to add or share and organize tags. The site was established as De.li.cio.us by Joshua Schachter in 2003 and acquired by Yahoo! in 2005, and purchased by AVOS Systems on April 27, 2011(Wikipedia).

Many researchers have suggested that social tagging has potential for user-based indexing (Golder and Huberman 2006; Lin et al. 2006; Tennis 2006). It can be recognized that the participation of users in building controlled vocabulary is being realized in a social tagging environment where users create or generate search keywords based on their intuitive principles. There has been exploratory research investigating tagging as a more accurate description of resources and reflection of more current terminology. Smith (2007) has asserted that tagging is better than subject headings by investigating tags assigned in LibraryThing and the subject headings assigned from $L C S H$. LibraryThing is a website that allows users to manage a personal catalog with their own books (Wikipedia).

\subsection{Methodology}

\subsection{Sampling of web documents}

Because this study is part of a larger research project that aims to investigate whether social tagging would enhance access to web resources and provide additional access points beyond those that are professionally-generated, web documents to be analyzed need to be located at a social tagging site as well as profes- 
sional indexing sites for comparison. Thus, web documents were randomly sampled when a web document is located at all three web sites, e.g., a social tagging site and two other professional indexing sites. We extracted tags from a social tagging site, Delicious. Delicious has a broad coverage of web resources, not limited to scholarly documents (e.g., journal articles on CiteUlike.org) or specific types of resources (e.g., photos and videos on Flickr). BUBL and Intute were selected as target subject gateways for professional indexing. Both BUBL and Intute cover various subjects and use traditional knowledge organization systems (see table 1). Only if a web document is found at all three locations (BUBL, Intute, and Delicious) were the tags assigned to the document at Delicious extracted.

\begin{tabular}{|c|c|c|}
\hline $\begin{array}{l}\text { Site charac- } \\
\text { teristics }\end{array}$ & BUBL & Intute \\
\hline Classification & DDC & UDC and DDC \\
\hline Keywords & $\mathrm{N} / \mathrm{A}$ & $\begin{array}{l}\text { Controlled: Several } \\
\text { thesauri for their subject } \\
\text { relevance and comprehen- } \\
\text { siveness, } \\
\text { e.g., SCIE for Social Wel- } \\
\text { fare, the Hasset, IBSS, } \\
\text { LIR for Law, and the } \\
\text { NLM MeSH headings for } \\
\text { Medicine } \\
\text { Uncontrolled: terms from } \\
\text { web sites' titles and de- } \\
\text { scriptions Intute indexers } \\
\text { provide }\end{array}$ \\
\hline $\begin{array}{l}\text { Subjects } \\
\text { covered }\end{array}$ & $\begin{array}{l}\text { Various } \\
\text { subjects }\end{array}$ & Various subjects \\
\hline Database & $\begin{array}{l}\text { Searchable } \\
\text { and } \\
\text { browsable }\end{array}$ & Searchable and browsable \\
\hline
\end{tabular}

Table 1. BUBL vs. Intute.

Sampling web documents was based on the 10 subject categories (see table 2) BUBL distinctively provides using DDC numbers as top-level categories. Each top-level category is arranged by about 10 second level sub-categories, sometimes more than 10 . In order to avoid potential bias in choosing documents at BUBL, a document was first randomly selected from the list of documents associated with a sub-category, and searched in turn at the other two sites, Intute and Delicious. The method of random sampling of documents was based on the True Random Number Generator (www.random.org). If the first document cho- sen randomly was not found in Intute or Delicious, then the next choice was made randomly until a web document satisfying the selection criteria was found. A total of 113 web documents were randomly selected for samples when choosing one document per sub-category.

\begin{tabular}{|l|l|}
\hline Top Categories & Subjects covered \\
\hline 000 Generalities & $\begin{array}{l}\text { Computing, Internet, Libraries, } \\
\text { Information Science }\end{array}$ \\
\hline $\begin{array}{l}\text { 100 Philosophy and } \\
\text { psychology }\end{array}$ & Ethics, Paranormal phenomena \\
\hline 200 Religion & Bibles, Religions of the world \\
\hline 300 Social sciences & $\begin{array}{l}\text { Sociology, Politics, Economics, } \\
\text { Law, Education }\end{array}$ \\
\hline 400 Language & $\begin{array}{l}\text { Linguistics, Language learning, } \\
\text { Specific languages }\end{array}$ \\
\hline $\begin{array}{l}500 \text { Science and } \\
\text { mathematics }\end{array}$ & $\begin{array}{l}\text { Physics, Chemistry, Earth Sci- } \\
\text { ences, Biology, Zoology }\end{array}$ \\
\hline 600 Technology & $\begin{array}{l}\text { Medicine, Engineering, Agricul- } \\
\text { ture, Management }\end{array}$ \\
\hline 700 The arts & $\begin{array}{l}\text { Art, Planning, Architecture, } \\
\text { Music, Sport }\end{array}$ \\
\hline $\begin{array}{l}800 \text { Literature and } \\
\text { rhetoric }\end{array}$ & Literature of specific languages \\
\hline $\begin{array}{l}900 \text { Geography and } \\
\text { history }\end{array}$ & Travel, Genealogy, Archaeology \\
\hline
\end{tabular}

Table 2. BUBL subject categories.

The selection criteria for sampling web documents were as follows:

- Subject categorizations for selecting documents was based on the top-level category at BUBL;

- A web document had to be located at all three web sites, BUBL, Intute, and Delicious; and,

- A web document having more than 50 taggers at Delicious was selected in order to have a sufficient number of taggers for investigating the characteristics of tagging.

\subsection{Collection of social tags}

A Java-based program was written for tag collection and tag pre-processing. Through the Delicious API, the program collected tags in a JSON (JavaScript Object Notation) format (Crockford 2006). For the period from February to March in 2010, Delicious top 20 tags assigned to 113 web documents were collected for analysis. The collected tags were normalized by checking spelling and word forms. 


\subsection{Data pre-processing}

Data pre-processing was conducted for the collected tags to exclude non-English tags or no tags. The collected tags were checked for spelling, acronyms or singular and plural forms. That is, this step included removing misspelled terms and integrating terms which have different forms of words such as noun, adjective, adverb, and gerund.

\subsubsection{An exact match between terms}

Based on discussion by Lancaster and Smith (1983), we used the following five rules for specifying an exact match between tags:

- Exactly corresponding including singular/plural variations

Ex) aurora to auroras, language to languages

- Variant spellings

Ex) organization to organisation

- Word forms (adjectival, noun, or verbal forms) Ex) medicine to medical

- Acronyms or abbreviations and full terms

Ex) National Center for Biotechnology Information to NCBI, biotechnology to biotech

- Compound terms

Ex) human/body to humanbody to human_body to human, body etc.

In terms of tags, Delicious does not have the feature of adding a space between two terms for a compound term, so if there is a dash, slash, or underscore between two terms, or if two terms were found at the same time in the list of tags from a tagger, they were regarded as a compound term. The dragon toolkit (Zhou, Zhang and $\mathrm{Hu}$ 2007), which is a WordNet (http://wordnet.princeton.edu/) based lemmatization tool, was used for checking for English words and stemming, which is for merging inflected forms of indexing words. Acronyms were checked in the Acronyms, Initialisms \& Abbreviations Dictionary (Reade and Romaniuk 2005).

\subsubsection{Term exclusion}

Because users at Delicious come from a worldwide audience, they might have different language backgrounds. Thus, if assigned tags are not in English (e.g., in Spanish, Korean, Chinese, etc.), they are excluded from the analysis. Furthermore, we developed a stoplist, which is a list of terms that can be excluded for processing (see Appendix 1). All tags were checked against the stoplist. The stoplist included an explicit list of the terms that Sen et al. (2006) define as subjective and personal tags, because those types of tags are not meaningful for describing subjects of documents. Table 3 provides the three types of tags and their definitions from Sen et al. and the related examples of tags identified.

\begin{tabular}{|l|l|l|}
\hline $\begin{array}{l}\text { Types of } \\
\text { tags }\end{array}$ & Definitions & $\begin{array}{l}\text { Examples of } \\
\text { identified tags }\end{array}$ \\
\hline $\begin{array}{l}\text { Factual } \\
\text { tags }\end{array}$ & $\begin{array}{l}\text { "identifies facts } \\
\text { about" a resource } \\
\text { e.g., people, places, } \\
\text { or concepts }\end{array}$ & $\begin{array}{l}\text { government, social- } \\
\text { security, finance etc. }\end{array}$ \\
\hline $\begin{array}{l}\text { Subjective } \\
\text { tags }\end{array}$ & $\begin{array}{l}\text { "express user opin- } \\
\text { ions” related to a } \\
\text { resource }\end{array}$ & $\begin{array}{l}\text { good, worth, rec- } \\
\text { ommend, toRead, } \\
\text { informative etc. }\end{array}$ \\
\hline $\begin{array}{l}\text { Personal } \\
\text { tags }\end{array}$ & $\begin{array}{l}\text { having "intended } \\
\text { audience of tag ap- } \\
\text { plied themselves" }\end{array}$ & $\begin{array}{l}\text { myDaughter, } \\
\text { forSon, etc. }\end{array}$ \\
\hline
\end{tabular}

Table 3. Sen et al. (2006) three types of tags.

\subsection{The scope of data analysis using FRBR}

The process of identifying bibliographic attributes of tags was based on the FRBR model. Because the attributes defined in the FRBR model were derived from "a logical analysis of the data that are typically reflected in bibliographic records" (IFLA 1998), the model supports a more systematic and meticulous analysis of the attributes of tags.

FRBR is a conceptual model of the "bibliographic universe" (works, texts, editions, documents and the like) that was developed by the International Federation of Library Associations and Institutions (IFLA 1998). It is intended to guide the development of systems for creating and managing bibliographic records. FRBR identifies four "Group 1" entity types (work, expression, manifestation, and item), defines relationships between them (a work is realized through an expression; an expression is embodied in a manifestation; a manifestation is exemplified by an item), and assigns characteristic attributes to each entity. For instance, works have form, expressions may be in a particular language, manifestations may have a typeface, and items may have a provenance. Figure 1 depicts Group 1 entities and relationships between them. The entity work is defined as "A distinct intellectual or artistic creation," expression as "the intellectual or artistic realization of a work in the form of alphanumeric, musical, or choreographic notation, sound, im- 


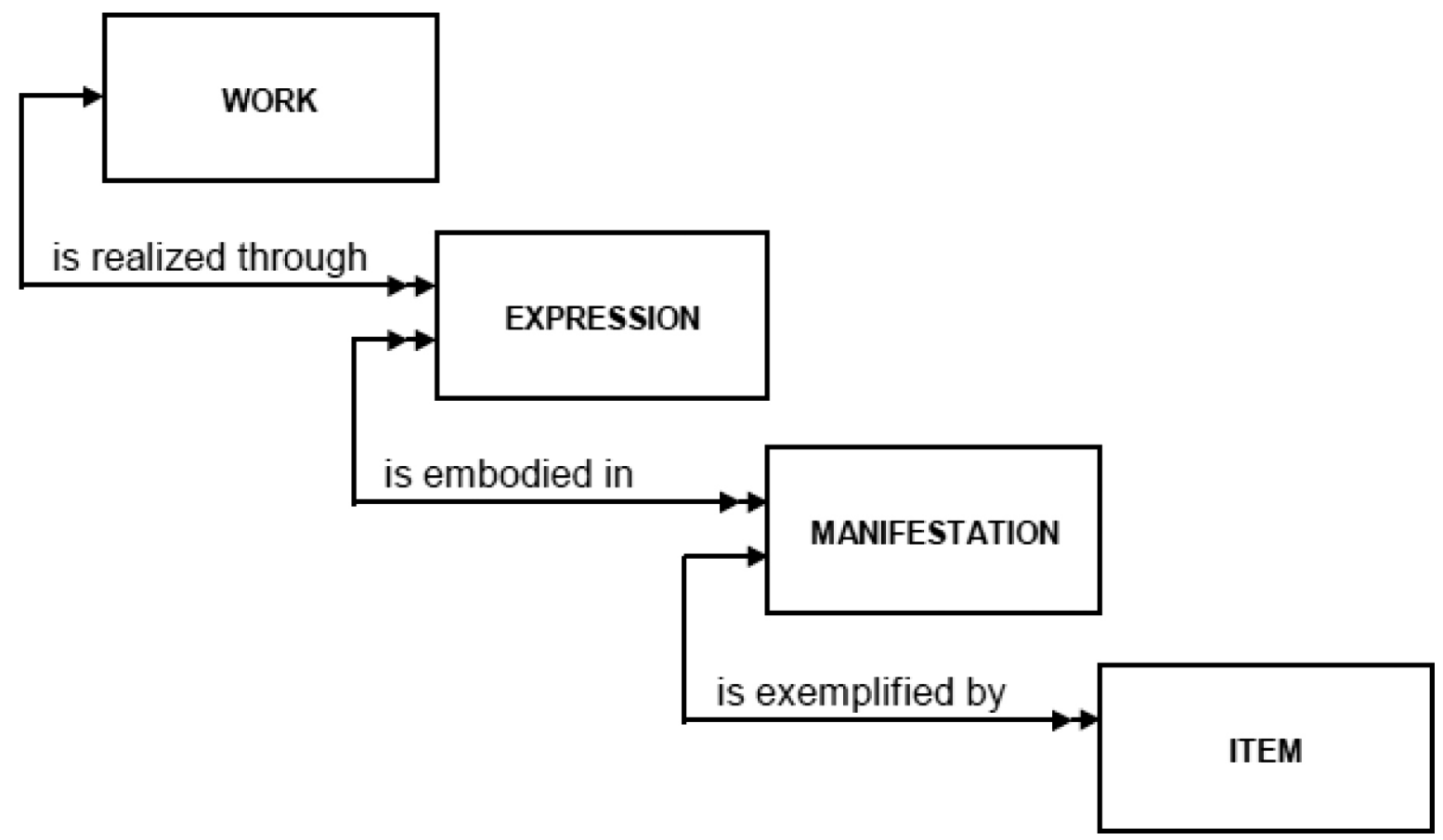

Figure 1. Group 1 entities and primary relationships (IFLA 1998)

age, object, movement, etc., or any combination of such forms," manifestation as "the physical embodiment of an expression of a work" and item as "a single exemplar of a manifestation” (IFLA 1998).

Each entity type is assigned a set of attributes. Works have attributes such as title and form; Expressions have a language attribute (translations of the same work are different Expressions); Manifestations have attributes like typeface; and Items have attributes such as condition and location.

In this research, the scope of data analysis focuses on web documents, so consideration of manifestation and item has been excluded. Only the entities Work and Expression were considered and the attributes of both Work and Expression entities were investigated in order to map the attributes of tags to attributes defined for those two entities. Table 4 illustrates the attributes of Work and Expression among FRBR group 1 entities (IFLA 1998). The attributes emphasized in bold face were only included for coding and other attributes were excluded for coding since it was determined that they are not applicable to web documents. Table 5 shows the final list of FRBR attributes for coding and the coding scheme and coding instructions for tag attributes during content analysis are included in Appendix 2. Since each attribute defined by FRBR is assumed to be disjoint (Renear and Choi 2006), this research set up the principle that coding should not overlap.

\begin{tabular}{|l|l|}
\hline Entities & Logical attributes \\
\hline Work & $\begin{array}{l}\text { title of the work } \\
\text { form of work } \\
\text { date of the work } \\
\text { other distinguishing characteristic } \\
\text { intended termination } \\
\text { intended audience } \\
\text { context for the work } \\
\text { medium of performance (musical work) } \\
\text { numeric designation (musical work) } \\
\text { key (musical work) } \\
\text { coordinates (cartographic work) } \\
\text { equinox (cartographic work) }\end{array}$ \\
\hline Expression & $\begin{array}{l}\text { title of the expression } \\
\text { form of expression } \\
\text { date of expression } \\
\text { language of expression } \\
\text { other distinguishing characteristic } \\
\text { extensibility of expression } \\
\text { revisability of expression } \\
\text { extent of the expression } \\
\text { summarization of content } \\
\text { context for the expression } \\
\text { critical response to the expression } \\
\text { use restrictions on the expression } \\
\text { sequencing pattern (serial) } \\
\text { expected regularity of issue (serial) } \\
\text { expected frequency of issue (serial) } \\
\text { type of score (musical notation) } \\
\text { medium of performance (musical notation } \\
\text { or recorded sound) } \\
\text { scale (cartographic image/object) } \\
\text { projection (cartographic image/object) }\end{array}$ \\
\hline
\end{tabular}




\begin{tabular}{|l|l|}
\hline Entities & Logical attributes \\
\hline Expression & $\begin{array}{l}\text { presentation technique (cartographic im- } \\
\text { age/object) } \\
\text { representation of relief (cartographic im- } \\
\text { age/object) } \\
\text { geodetic, grid, and vertical measurement } \\
\text { (cartographic image/object) } \\
\text { recording technique (remote sensing im- } \\
\text { age) } \\
\text { special characteristic (remote sensing im- } \\
\text { age) } \\
\text { technique (graphic or projected image) }\end{array}$ \\
\hline
\end{tabular}

Table 4. FRBR Group 1 entities and logical attributes

\subsection{Intercoder reliability test}

The content analysis on tag attributes was conducted on a total of 113 web documents regarding 11 attribute categories defined by FRBR (five categories from Work entity and six categories from Expression en- tity). In order to improve research reliability and objectivity in the analysis of tag attributes, another coder was recruited and the intercoder reliability between two coders was calculated. The recruited coder was a Ph.D. candidate in Library and Information Science. Two coders independently coded tags based on the coding instruction. A sample of coded web document is provided in Appendix 3.

Regarding the sub sample size for the inter-coder reliability test, Wimmer and Dominick (1987) recommend that between $10 \%$ and $25 \%$ of the data should be investigated to test intercoder reliability. In this research, $25 \%$ of the web document collection selected for data analysis is randomly sampled using the True Random Number Generator (www.random.org). For example, under 000 Generalities categories, the number of selected documents was 8 , so sub-sample size in this category is 2 . Thus, among 113 web documents, 29 web documents are selected for the inter-

\begin{tabular}{|c|c|c|}
\hline Entities & Logical attributes & Description \\
\hline \multirow[t]{5}{*}{ Work } & title of the work (WT) & $\begin{array}{l}\text { The title of the work is the word, phrase, or group of characters naming the work. } \\
\text { There may be one or more titles associated with a work. }\end{array}$ \\
\hline & form of work (WF) & $\begin{array}{l}\text { The form of work is the class to which the work belongs (e.g., novel, play, poem, essay, } \\
\text { biography, symphony, concerto, sonata, map, drawing, painting, photograph, etc.). }\end{array}$ \\
\hline & $\begin{array}{l}\text { date of the work } \\
\text { (WD) }\end{array}$ & $\begin{array}{l}\text { The date of the work is the date (normally the year) the work was originally created. } \\
\text { The date may be a single date or a range of dates. In the absence of an ascertainable } \\
\text { date of creation, the date of the work may be associated with the date of its first pub- } \\
\text { lication or release. }\end{array}$ \\
\hline & $\begin{array}{l}\text { intended audience } \\
\text { (WI) }\end{array}$ & $\begin{array}{l}\text { The intended audience of the work is the class of user for which the work is intended, } \\
\text { as defined by age group (e.g., children, young adults, adults, etc.), educational level } \\
\text { (e.g., primary, secondary, etc.), or other categorization. }\end{array}$ \\
\hline & $\begin{array}{l}\text { context for the work } \\
\text { (WC) }\end{array}$ & $\begin{array}{l}\text { Context is the historical, social, intellectual, artistic, or other context within which } \\
\text { the work was originally conceived (e.g., the } 17 \text { th century restoration of the monarchy } \\
\text { in England, the aesthetic movement of the late } 19 \text { th century, etc.). }\end{array}$ \\
\hline \multirow[t]{6}{*}{ Expression } & form $(\mathrm{EF})$ & $\begin{array}{l}\text { The form of expression is the means by which the work is realized (e.g., through alpha- } \\
\text { numeric notation, musical notation, spoken word, musical sound, cartographic image, } \\
\text { photographic image, sculpture, dance, mime, etc.). }\end{array}$ \\
\hline & date (ED) & $\begin{array}{l}\text { The date of expression is the date the expression was created (e.g., the date the particu- } \\
\text { lar text of a work was written or revised, the date a song was performed, etc.). The } \\
\text { date may be a single date or a range } \\
\text { of dates. In the absence of an ascertainable date of expression, the date of the expres- } \\
\text { sion may be associated with the date of its publication or release. }\end{array}$ \\
\hline & $\begin{array}{l}\text { language of expression } \\
\text { (EL) }\end{array}$ & $\begin{array}{l}\text { The language of the expression is the language in which the work is expressed. The lan- } \\
\text { guage of the expression may comprise a number of languages, each pertaining to an in- } \\
\text { dividual component of the expression. }\end{array}$ \\
\hline & $\begin{array}{l}\text { summarization of con- } \\
\text { tent (ES) }\end{array}$ & $\begin{array}{l}\text { A summarization of the content of an expression is an abstract, summary, synopsis, } \\
\text { etc., or a list of chapter headings, songs, parts, etc. included in the expression. }\end{array}$ \\
\hline & $\begin{array}{l}\text { use restrictions on the } \\
\text { expression }(E U)\end{array}$ & $\begin{array}{l}\text { Use restrictions are restrictions on access to and use of an expression. Use restrictions } \\
\text { may be based in copyright, or they may extend beyond the protections guaranteed in } \\
\text { law to the owner of the copyright. }\end{array}$ \\
\hline & $\begin{array}{l}\text { technique (graphic or } \\
\text { projected image) (ET) }\end{array}$ & $\begin{array}{l}\text { Technique is the method used to create a graphic image (e.g., engraving, etc.) or to re- } \\
\text { alize motion in a projected image (e.g., animation, live action, computer generation, } \\
3 \mathrm{D} \text {, etc.). }\end{array}$ \\
\hline
\end{tabular}

Table 5. FRBR attributes and description (IFLA Study Group 1998). 
Y. Choi. A Practical Application of FRBR for Organizing Information in Digital Environments

coder reliability test (Table 6 ). Thus, among 1,879 tags assigned to 113 documents, 442 tags assigned to 29 web documents are coded for intercoder reliability.

\begin{tabular}{|l|c|c|c|}
\hline $\begin{array}{l}\text { Top } \\
\text { Categories }\end{array}$ & $\begin{array}{c}\text { The } \\
\text { number of } \\
\text { selected } \\
\text { documents }\end{array}$ & $\mathbf{2 5 \%}$ & $\begin{array}{c}\text { The number } \\
\text { of documents } \\
\text { for inter- } \\
\text { coder } \\
\text { reliability }\end{array}$ \\
\hline $\begin{array}{l}\text { 000 Generali- } \\
\text { ties }\end{array}$ & 8 & 2 & 2 \\
\hline $\begin{array}{l}\text { 100 Philosophy } \\
\text { and psychology }\end{array}$ & 6 & 1.5 & 2 \\
\hline 200 Religion & 12 & 3 & 3 \\
\hline $\begin{array}{l}300 \text { Social sci- } \\
\text { ences }\end{array}$ & 12 & 3 & 3 \\
\hline 400 Language & 9 & 2.25 & 2 \\
\hline $\begin{array}{l}\text { 500 Science and } \\
\text { mathematics }\end{array}$ & 10 & 2.5 & 3 \\
\hline 600 Technology & 8 & 2 & 2 \\
\hline 700 The arts & 21 & 5.25 & 5 \\
\hline $\begin{array}{l}\text { 800 Literature } \\
\text { and rhetoric }\end{array}$ & 15 & 3.75 & 4 \\
\hline $\begin{array}{l}\text { 900 Geography } \\
\text { and history }\end{array}$ & 12 & 3 & 3 \\
\hline Total & 113 & 28.25 & 29 \\
\hline
\end{tabular}

Table 6. The number of documents for intercoder reliability test.

There are a number of measures of intercoder reliability. Lombard, Synder-Duch and Bracken (2005) describe several measures commonly used in social science and communication such as percent agreement,

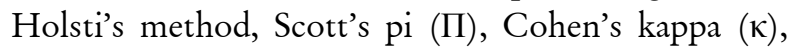
and Krippendorff's alpha $(\alpha)$. The percent agreement index has advantages of simplicity and ease of calculation, but it records only agreements and disagreements. This index also has a flaw in that it does not account for agreement occurring by chance. Holsti's method (1969) is a variation on the percent agreement index; it accounts for the situation in which the coders evaluate different units. But, when two coders evaluate the same units, the results by Holsti's method are the same as those by the percentage agreement index of reliability because it calculates percent agreement between two coders (Hayes 2007; Lombard, SnyderDuch and Bracken 2005). Scott's pi (1955) takes into account both the observed proportion of agreement and the proportion that would be expected by chance. Yet, Scott's pi has a limitation to two coders and nominal data (Hayes 2007). On the other hand, several researchers (Bakeman 2000; Dewey 1983) recommend Cohen's kappa ( $\kappa)$, one of the widely used measures for intercoder reliability. Cohen's kappa is identical to Scott's pi in that it accounts for agreement expected by chance. The equation for kappa $(\kappa)$ is as follows:

$$
\kappa=\frac{\operatorname{Pr}(\omega)-\operatorname{Pr}(e)}{1-\operatorname{Pr}(e)}
$$

$\operatorname{Pr}(a)$ : agreement, observed

$\operatorname{Pr}(e)$ : agreement, expected by chance

Unlike Scott's pi, the assumption of kappa is that the same two coders have coded all units, so it cannot be applicable to situations where different pairs of coders have coded different subsets of the units (Craig 1981). Krippendorff $(1978,1987,2004)$ also criticizes that Cohen's kappa $(\kappa)$ is not appropriate for testing intercoder agreement. Krippendorff insists that because Cohen's kappa ( $\kappa$ ) defines chance as "the statistical independence of two coders' use of categories," the categories one coder uses are not predictable from the categories the other coder uses.

Krippendorff's alpha $(\alpha)(1980)$ is also a commonly used measure for intercoder reliability. It is considered to be very flexible as it can account for different sample sizes and missing data, and can be applied to any number of observers, any number of categories, and any level of measurements, e.g., nominal, ordinal, interval, ratio, and more (Hayes 2007; Lombard, Snyder-Duch and Bracken 2005; Krippendorff 2004). Alpha $(\alpha)$ 's general form is as follows (Krippendorff 2004):

$$
\alpha=1-\frac{D_{o}}{D_{e}}
$$

$\mathrm{D}_{\mathrm{o}}$ : disagreement, observed

$\mathrm{D}_{\mathrm{e}}$ : disagreement, expected by chance

$\alpha=1$ means observers agree perfectly, i.e., perfect reliability and the value of $\mathrm{D}_{\mathrm{o}}$ is zero. Also, $\alpha=0$ means the absence of reliability, and $D_{o}=D_{e}$. Thus, $\alpha$ 's range is explained by:

$$
1 \geq \alpha \geq 0 \quad\left\{\begin{array}{l}
- \text { Systematic disagreement } \\
\pm \text { Sampling errors }
\end{array}\right.
$$

Although many reliability measures have been used and discussed by several researchers, there has been no consensus on a best measure for reliability, and each index has its own qualities and assumptions (Lombard 
et al., 2005; Taylor \& Watkinson, 2007). In this research, therefore, four indices mentioned above, i.e.,

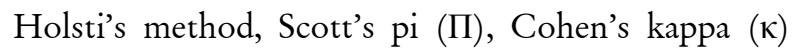
and Krippendorff's alpha $(\alpha)$, are used to test intercoder reliability. Calculating and reporting reliability by using more than one index is a preferred approach that can take into account any bias or weaknesses caused by the results from one (Lombard, SnyderDuch and Bracken 2005).

\subsection{Results}

The results of the analyses of tag attributes based on the FRBR model illustrated important tag attributes and tagging behaviors by subject.

\subsection{Results of the intercoder reliability test}

The intercoder reliability test was calculated by using the Holsti method, Scott's pi, Cohen's kappa and Krippendorf's alpha. In terms of criteria for acceptability, index scales are analogous but it has been cautioned that different indices measure different things (Lombard, Snyder-Duch and Bracken 2005; Neuendorf 2002). Therefore, a satisfactory level depends on the index used (Taylor and Watkinson 2007). Holsti (1969) suggests the agreement level of $85 \%$ or more for the acceptable level. Banerjee et al. (1999) suggest that Cohen's kappa levels should exceed 0.75 for excellent agreement beyond chance, between 0.40-0.70 is fair to good agreement beyond chance, and $<0.40$ is poor agreement. Landis and Koch (1977) have provided a more detailed list of interpretation of kappa: $0.81-1.00$ is almost perfect agreement, $0.61-0.80$ is substantial agreement, $0.41-0.60$ is moderate agree- ment, $0.21-0.40$ is fair agreement, $0.0-0.20$ is slight agreement and $<0$ is poor agreement. For the case of Krippendorff's alpha, it has been suggested to exceed 0.70 for excellent agreement (Krippendorff 2004; Taylor and Watkinson 2007). In this research, in four indices, the results of the intercoder reliability test showed an excellent agreement as shown in Table 7.

\begin{tabular}{|l|l|c|}
\hline Measure of reliability & Value & \multirow{2}{*}{ Units } \\
\hline Holsti & .8824 & \multirow{2}{*}{442} \\
\cline { 1 - 2 } Scott's pi & .7963 & \\
\cline { 1 - 2 } Cohen's kappa & .7963 & \\
\cline { 1 - 2 } Krippendorff's Alpha & .7965 & \\
\hline
\end{tabular}

Table 7. Results of intercoder reliability test using four indices.

In order to investigate the degree of reliability among subject areas, the reliability test on each subject area was performed. The results of intercoder reliability test using four indices demonstrated that the Literature subject showed the lowest level of agreement among 10 different subject areas (Figure 2).

Table 8 illustrates the cross-tabulation of coded data by two coders on the Literature subject. It was found that there was especially low agreement between two coders on two attribute categories, i.e., WF (Form of Work entity) and EF (Form of Expression entity). The examples of those tags were Books, Database, Magazine, Journal, and Encyclopedia. This disagreement on those attributes was caused by the fact that the documents, tagged with a term "Book," include the list of books or provide a feature of searching for books rather than books themselves (see Table 9). However, current definitions provided

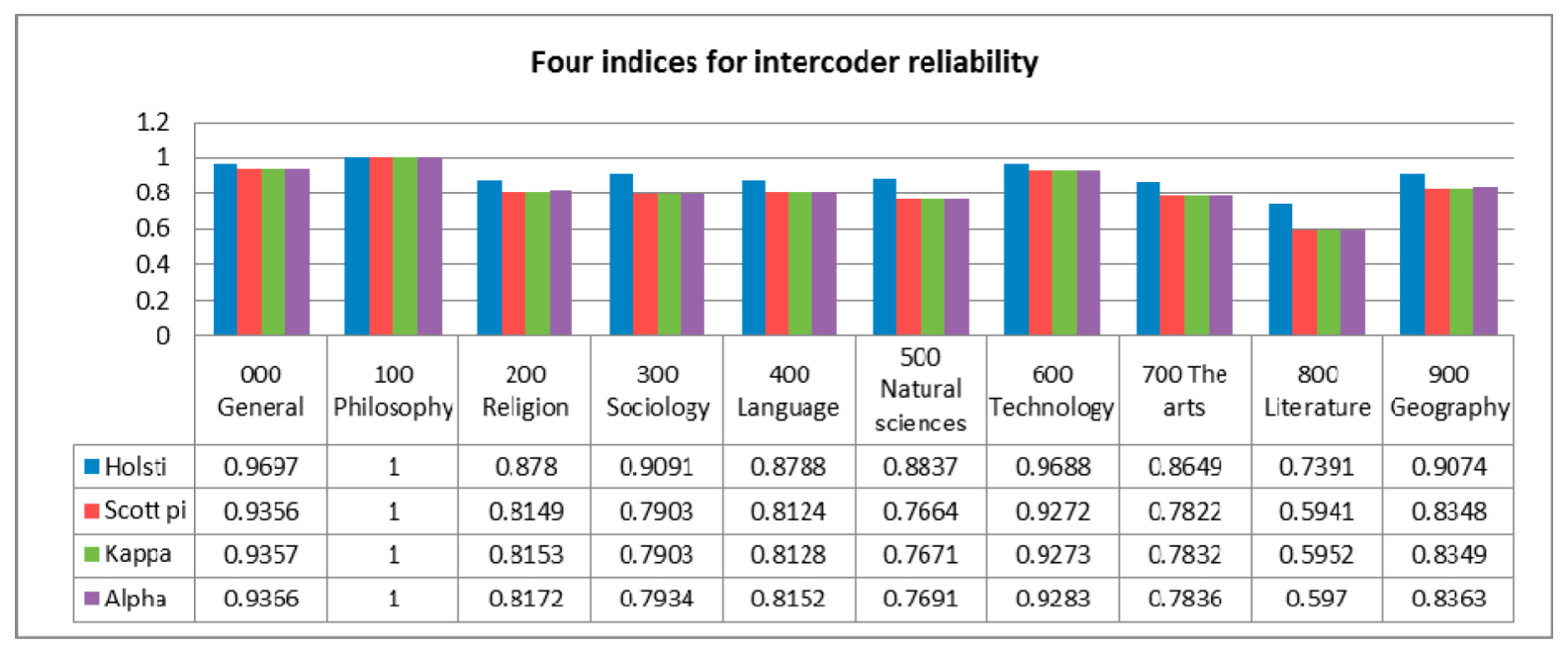

Figure 2. The results by four indices for intercoder reliability 
Y. Choi. A Practical Application of FRBR for Organizing Information in Digital Environments

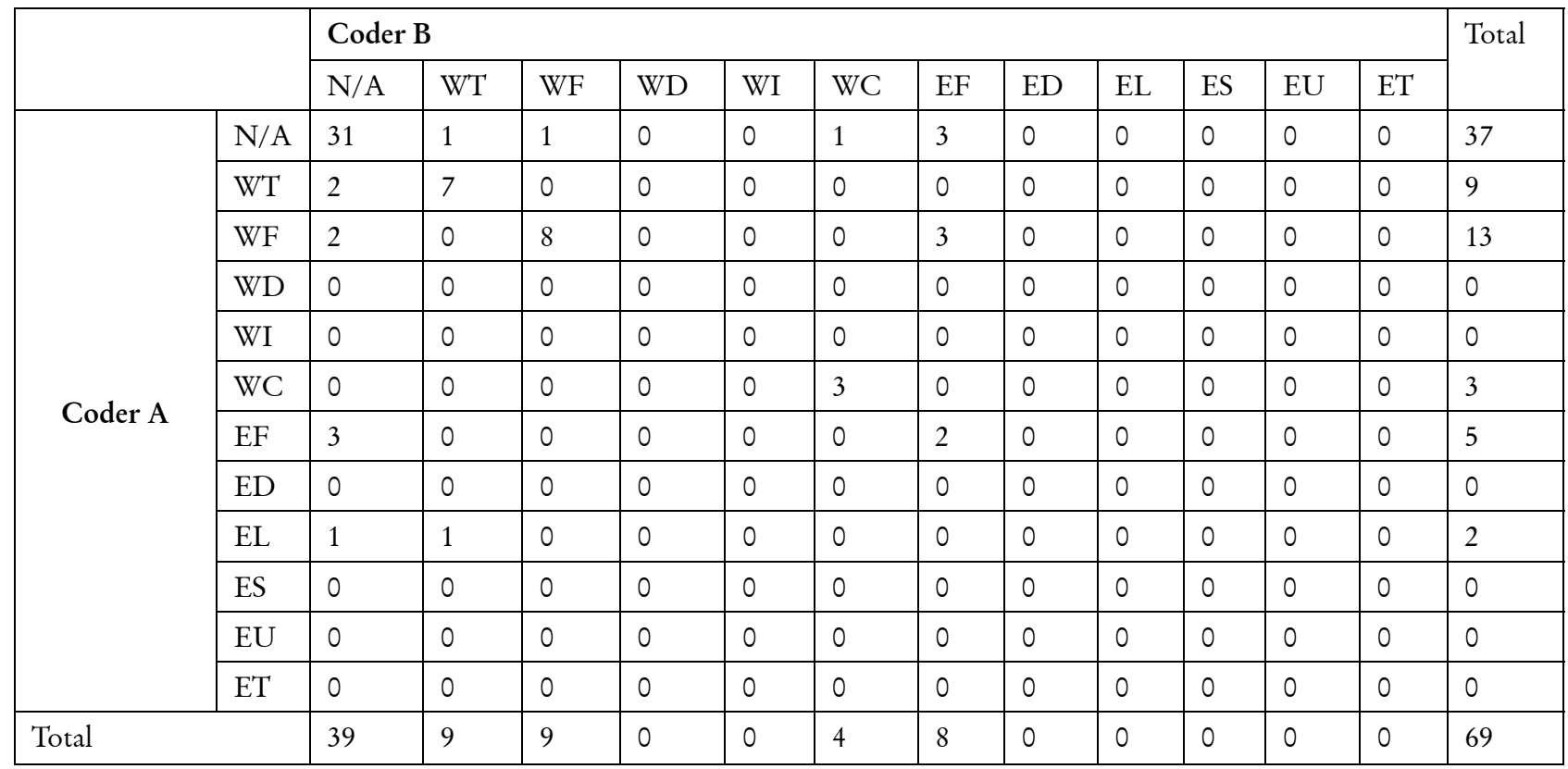

Table 8. Crosstabulation of coded data (Literature subject)

by FRBR do not explicitly distinguish these two attributes (i.e., WF and EF) about web documents. To make FRBR more applicable in practical terms, FRBR should be able to describe digital heterogeneous media resources that are available in various formats and attributes.

\begin{tabular}{|l|l|}
\hline Document & Description \\
\hline $\begin{array}{l}\text { 808.8 Google Book } \\
\text { Search: }\end{array}$ & $\begin{array}{l}\text { "helps users search within } \\
\text { and discover books using } \\
\text { digital page-scans pre- } \\
\text { sented in a simple ebook } \\
\text { format" (provided by } \\
\text { BUBL) }\end{array}$ \\
\hline $\begin{array}{l}\text { 809 Literary history: } \\
\text { http://literaryhistory.com/ }\end{array}$ & $\begin{array}{l}\text { "provides selected anno- } \\
\text { tated links to critical arti- } \\
\text { cles on British and Ameri- } \\
\text { can literatures" (provided } \\
\text { by Intute) }\end{array}$ \\
\hline
\end{tabular}

Table 9. Web documents tagged with the term "book"

As discussed above, the results of the intercoder reliability test (see Table 7) were very satisfactory with excellent agreement for all four indices (Banerjee et al. 1999; Holsti 1969; Krippendorff 2004; Landis and Koch 1977; Taylor and Watkinson 2007), but it is very important to note that reliability and validity are different. Reliability is concerned with the consistency of the measurement while validity is related to the strengths of the results. Krippendorff $(2008,357)$ asserts that validity is about truth and reliability relates to trust. He also argues that "reliability cannot guarantee validity." Thus, the results of the intercoder reliability test do not determine the validity of the conclusions on tag analysis, but instead, they contribute to enhancing confidence in reliability. In the following sections, the results on the analysis of tag attributes are discussed for the whole collection of documents.

\subsection{Categories of tag attributes}

During the process of content analysis on tag attributes, if a tag was determined to be a term related to subjects or topics describing documents, the tag was categorized as "Subject." Also, if a tag was identified as a term that cannot be categorized into any of the categories defined by FRBR, the tag was categorized as "Others." Finally it was determined that the tags included in the "Others" would be assigned to subcategories such as Feature, Utilization, and Institution etc, and the discussion of those tags will be provided later. The findings on the analysis of tag attributes are depicted in Figure 3. Figure 3 illustrates that among tags assigned to the sampled documents, in the pie chart, $26 \%$ of tags were subject-related terms, $27 \%$ of tags were matched into the attributes of FRBR, and $47 \%$ of tags were categorized into other attributes. This illustrates that many tags (about 74\%) include additional properties beyond subject or topic terms. 


\subsection{Tagging behaviors}

In order to investigate whether the attributes of tags could be described by the FRBR attributes, a matching process was conducted between tags and FRBR attributes. Tags were identified based on the attribute categories defined by FRBR as shown in Table 10. Table 10 excludes the WT (Title of work entity) category where tags consist of terms used in the title of the document. Regarding the tags related to subject terms, in Language, Literature, and Geography subject, the number of subject-related tags was relatively low (Figure 4 and Figure 5).

Figures 6-8 below illustrate that in terms of web documents in those three subjects, taggers tended to focus more on other properties of documents rather than the subjects or topics of documents, that is, the Form of Work entity (WF) and Form of Expression entity (EF). Since the figures mainly show the comparison of subject-related tags and FRBR categorized tags, the "Others" category is not represented in those figures. A more in-depth analysis was conducted on the tendency of tagging in terms of 11 FRBR attribute categories. Figures 9 and 10 demonstrate that taggers tend to mainly assign tags on attributes related to WT (Title attribute of FRBR Work entity) and WF.

In order to investigate the features and patterns of social tagging in assigning attributes matching those defined in FRBR, a thorough examination was conducted on tags categorized by FRBR attributes. Figure 11 and 12 show tag frequency on the categories defined by FRBR in terms of 10 different subject areas.

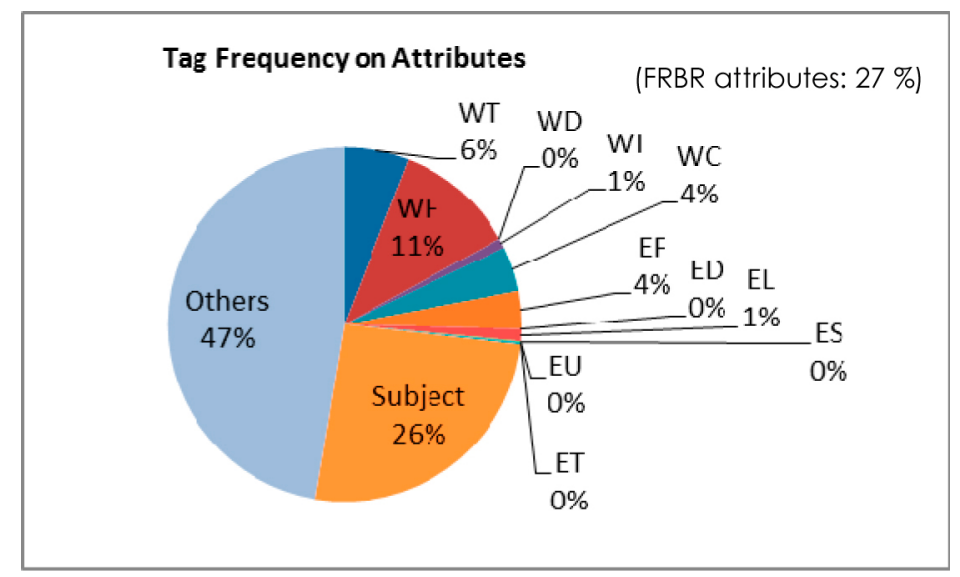

Figure 3. Tag frequency and attribute categories

\begin{tabular}{|l|l|l|}
\hline Entities & Attributes & Identified tags \\
\hline Work & Form of work (WF) & $\begin{array}{l}\text { reference, journal, research, magazine, news, paper, article, dic- } \\
\text { tionary, archive, database, directory, book, essay, scripture, } \\
\text { gov-doc, encyclopedia, glossary, tutorial }\end{array}$ \\
\cline { 2 - 3 } & Date of work (WD) & N/A \\
\cline { 2 - 3 } & Intended audience (WI) & $\begin{array}{l}\text { baby, doctor, engineer, artist, dealer, architect, } \\
\text { author, writer, children, illustrator, poet, teacher }\end{array}$ \\
\cline { 2 - 3 } & Context for the work (WC) & $\begin{array}{l}\text { world, war, uk, primary source, 18c, India, usa, middleeast, } \\
\text { federal, Boccaccio, Medieval, ancient }\end{array}$ \\
\hline \multirow{5}{*}{ Expression } & Form (EF) & $\begin{array}{l}\text { music, ebook, texts, iconography, images, statistics, word, } \\
\text { video, vocabulary, etext, bibtex, pictures, photos, multimedia, } \\
\text { graphic, audio, sound, illustration, posters }\end{array}$ \\
\cline { 2 - 3 } & & N/A \\
\cline { 2 - 3 } & Date (ED) & English, Hebrew, Greek, \\
\cline { 2 - 3 } & Language of expression (EL) & list \\
\cline { 2 - 3 } & Summarization of content (ES) & N/A \\
\cline { 2 - 3 } & Use restrictions on the expression(EU) & graphic organizer, flash \\
\cline { 2 - 3 } & Technique (graphic or projected image) (ET) & (E) \\
\cline { 2 - 4 }
\end{tabular}

Table 10. Identified tags and related FRBR attributes 


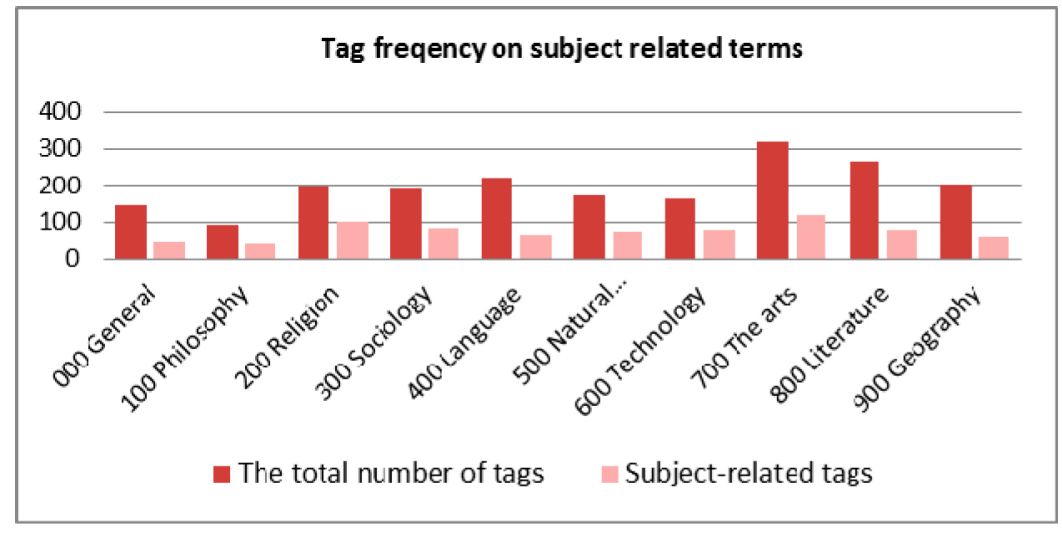

Figure 4. Tag frequency on subject related terms

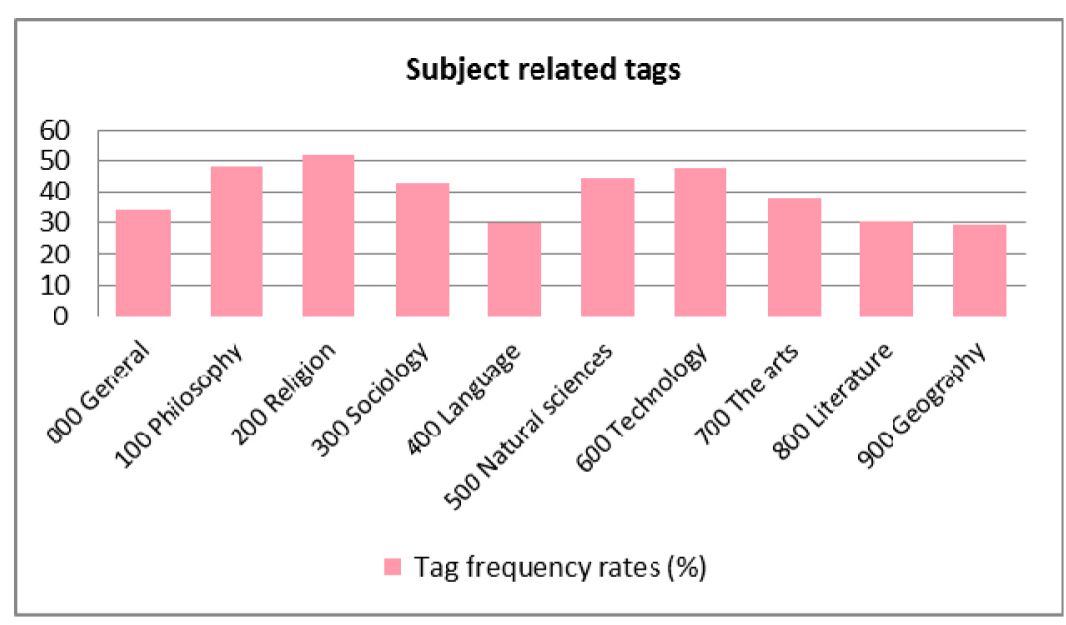

Figure 5. Tag frequency rates on subject related terms

\subsection{FRBR Intended audience of Work entity (WI)}

As shown in Figure 11 and 12, the tag frequency on FRBR attributes formed a different tendency depending on subject categories. For example, in three subject areas, Technology, Arts and Literature subjects, the tag frequency on FRBR WI (intended audience) attribute was relatively high (see Figure 13), which means that taggers tend to consider audience in these subject areas. In the Technology subject, the tags applied to the WI category were doctor, engineer etc. On the other hand, in the Art subject, the tags were artists, architects, and dealers etc. In the Literature subject, the tags were author, poet, children, and writer etc. It can be inferred that high frequency on the WI category in those subject areas reflects the characteristics of different user needs for metadata. For example, in Literature, many documents are intended for adults, so if a document is related to resources for children, taggers tend to specifically indicate it by assigning a tag, "children" as the intended audience.

\subsection{FRBR Form of Expression entity (EF)}

In terms of Natural sciences and Geography, the findings on tag frequency of the EF category showed relatively high proportions (respectively, 21\% and $28 \%$ ) in comparison with those of other subject categories (Figure 14). In both subject areas, the tags assigned to the EF category were image, video, picture, and photos etc. It implies that web documents in Natural sciences and Geography are mainly characterized by taggers with focus on specific forms.

\subsection{Other tag attributes}

Besides the categories mentioned above, the proportion of tags having other types of attributes was $47 \%$ (Figure 15). Concerning the other attributes of tags that were not categorized into any attribute categories (FRBR attributes and subject categories), three subcategories were developed to sort out those tags, i.e., Feature, Utilization, and Institution. Also, if a tag could not be assigned to any of the subcategories 
Tag Frequency: Subject vs. FRBRAttributes 400 Language

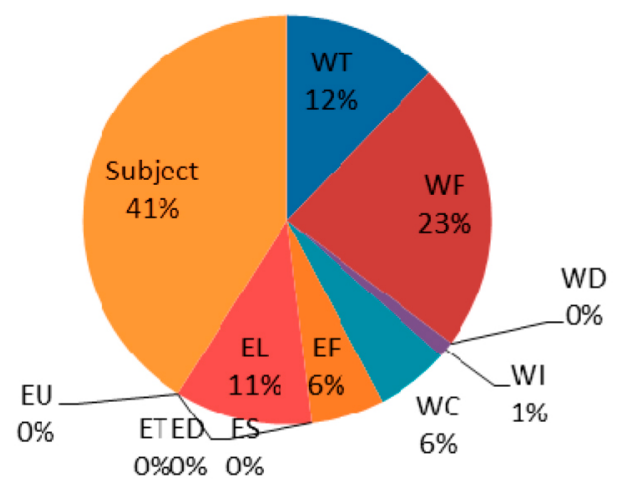

Figure 6. Tag frequency rates on Language subject.

Tag Frequency: Subject vs. FRBR Attributes $\mathbf{8 0 0}$ Literature

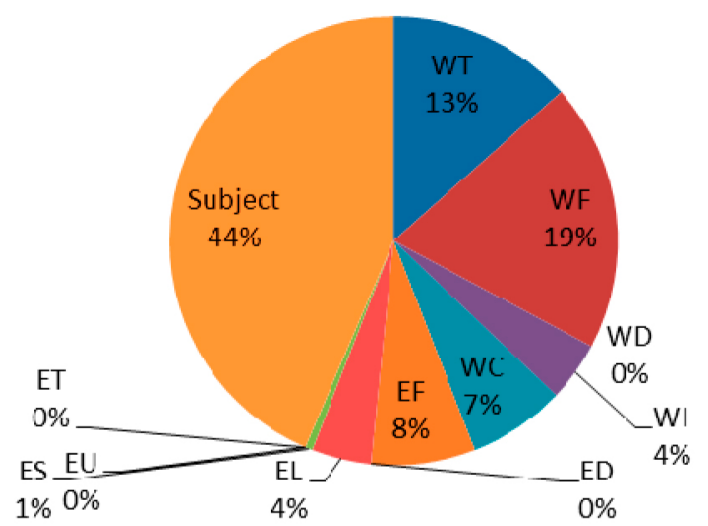

Figure 7. Tag frequency rates on Literature subject.

Tag Frequency: Subject vs. FRBR Attributes 900 Geography

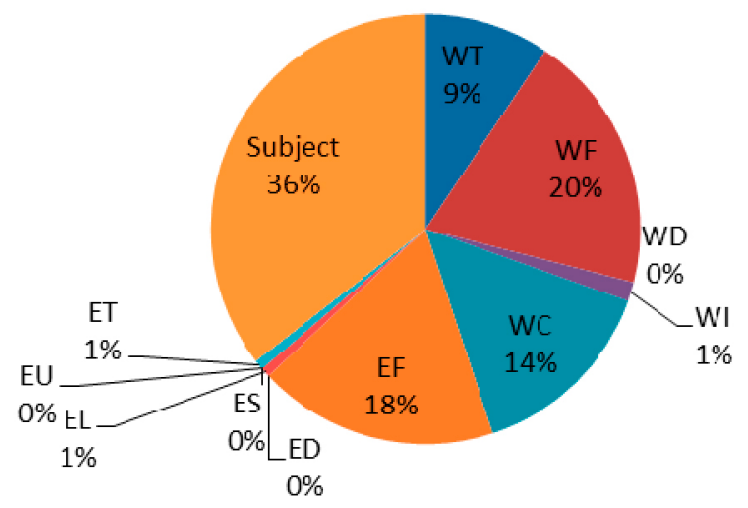

Figure 8. Tag frequency rates on Geography subject. 
Y. Choi. A Practical Application of FRBR for Organizing Information in Digital Environments

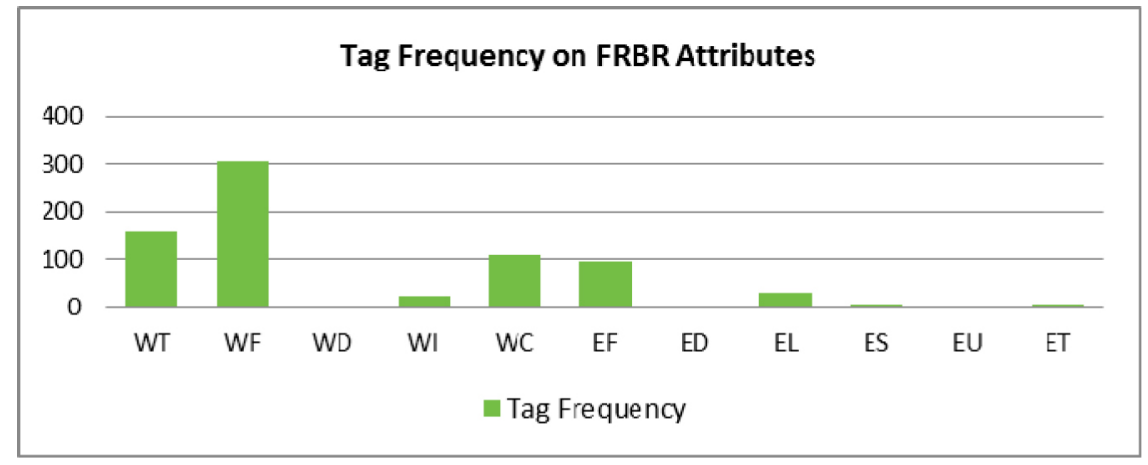

Figure 9. Tag frequency on FRBR attributes (bar graph)

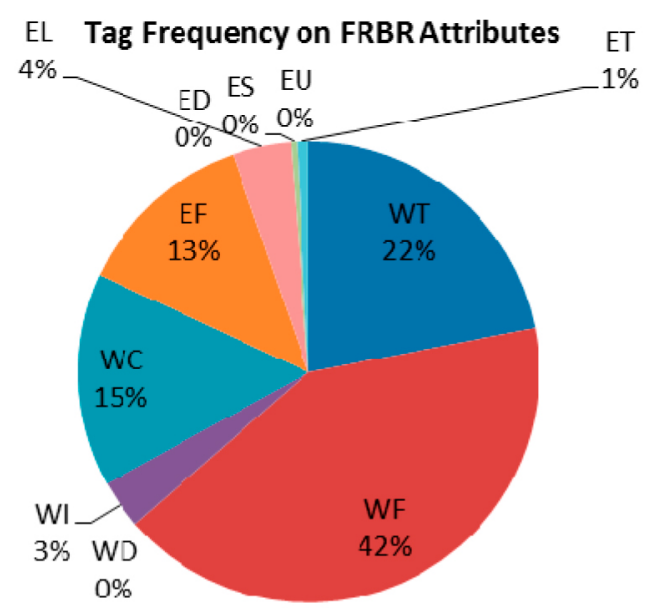

Figure 10. Tag frequency on FRBR attributes (pie chart)

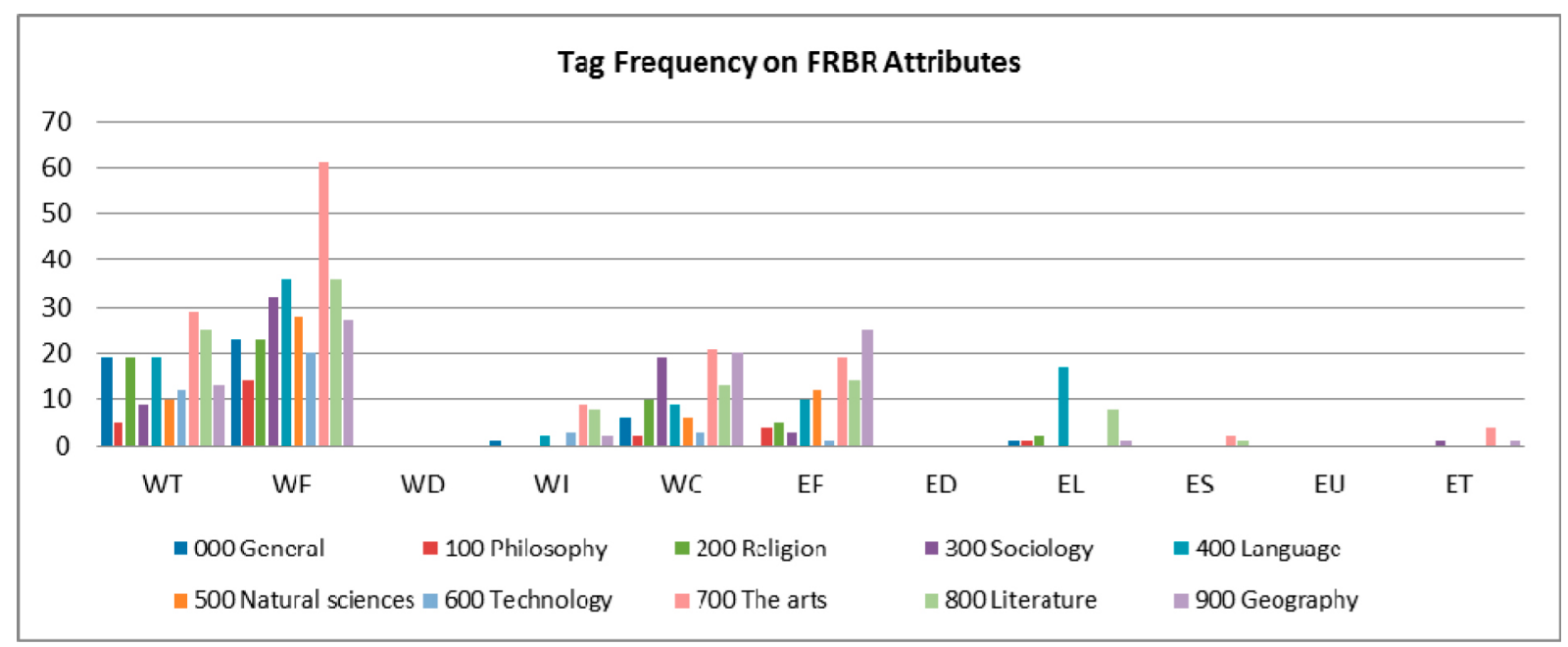

Figure11. Tag Frequency on FRBR attributes over all subjects (bar graph) 


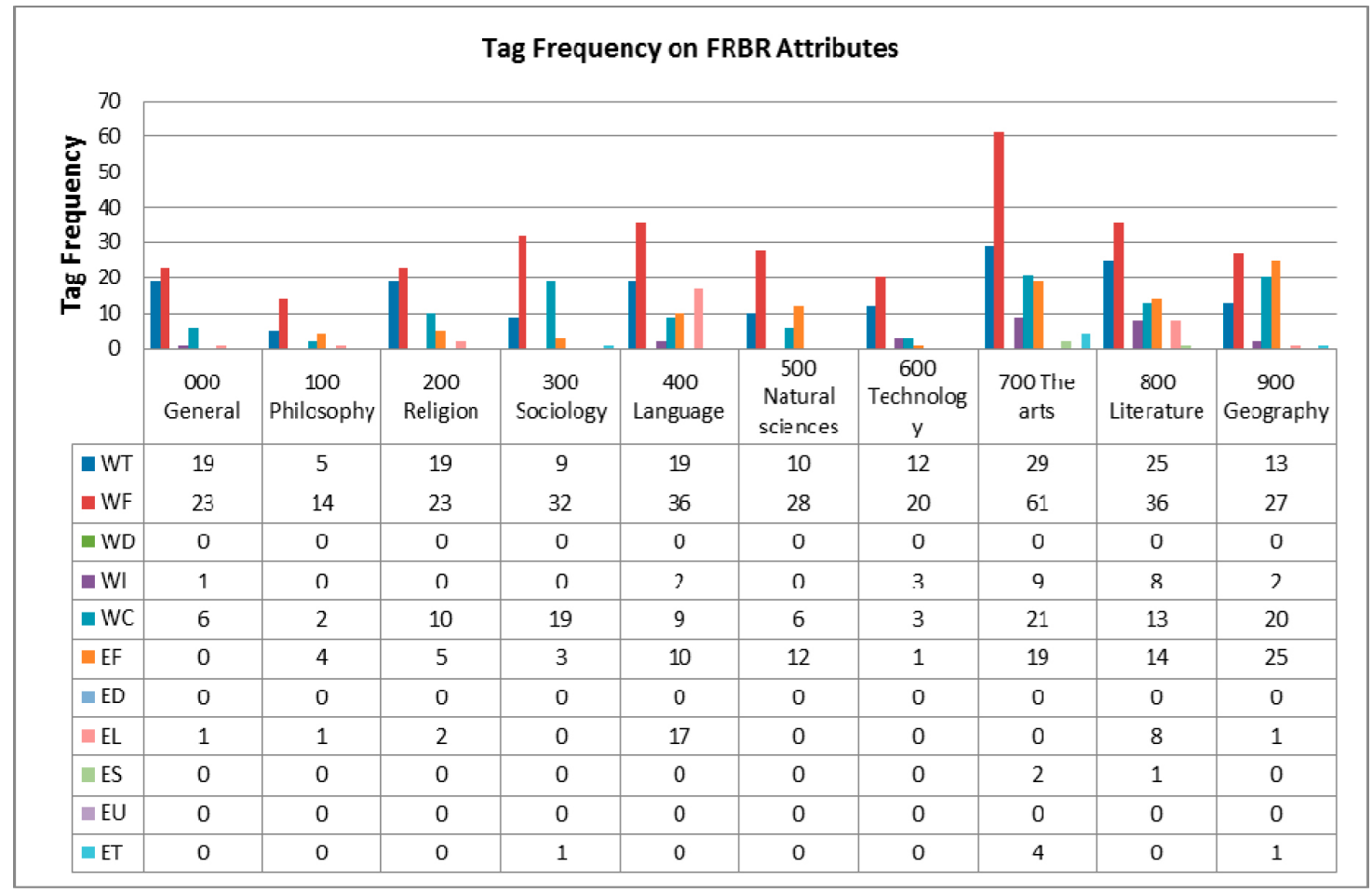

Figure12. Tag Frequency on FRBR attributes over all subjects (bar graph II)

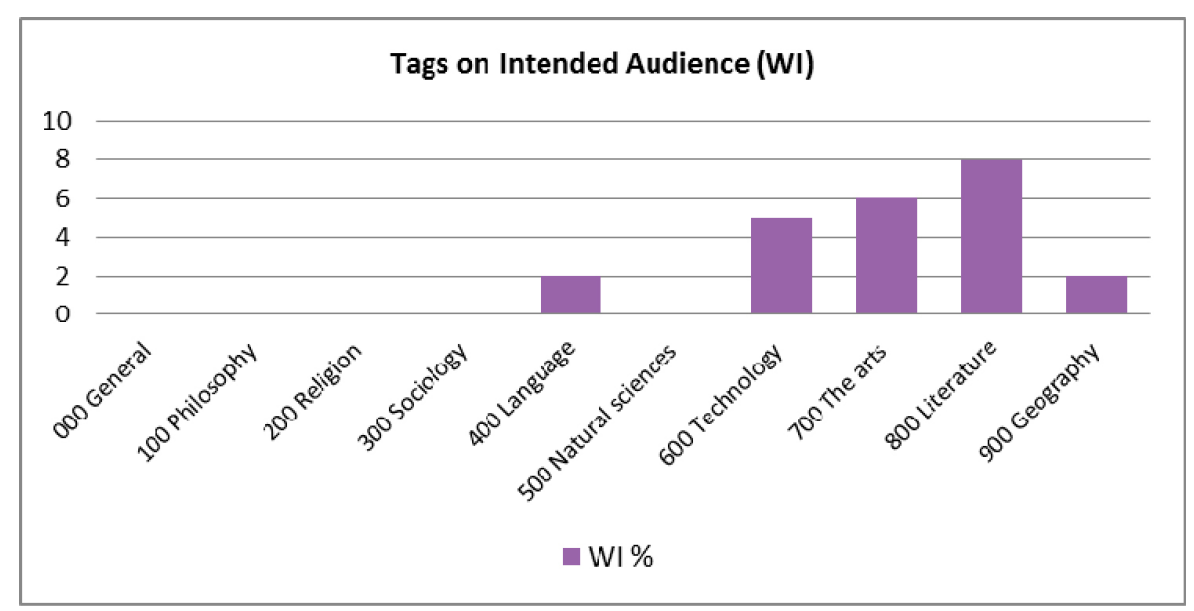

Figure 13. Tags on intended audience (WI)

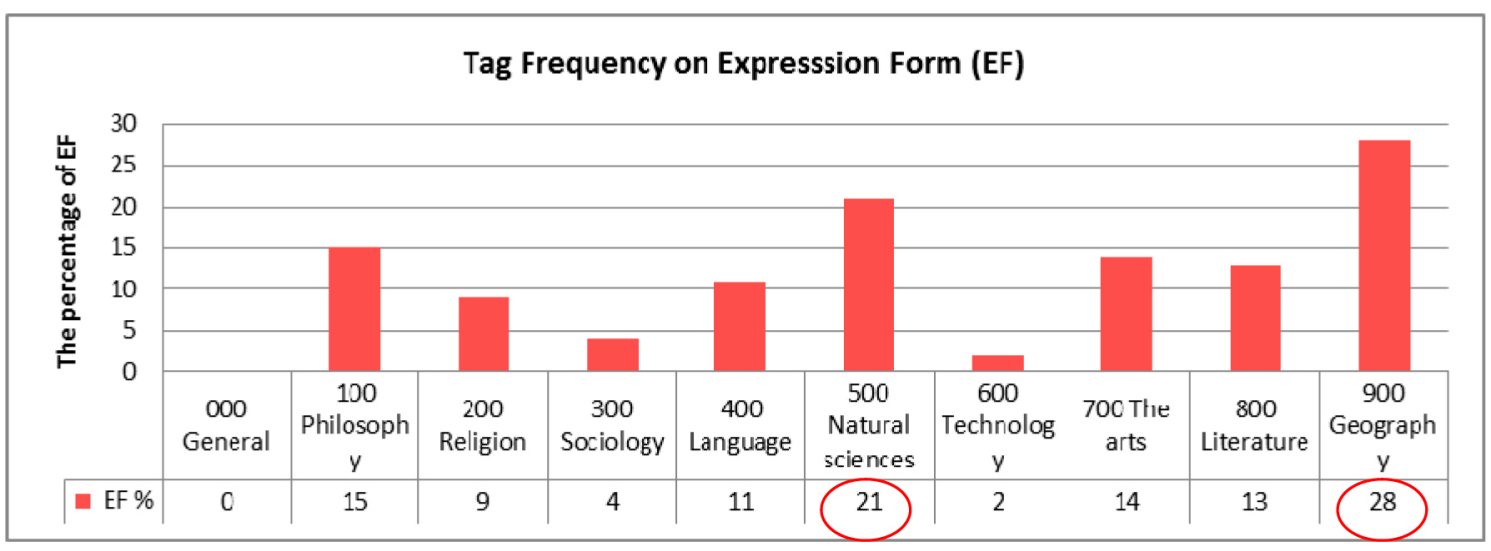

Figure 14. Tags on forms of Expression (EF) 
mentioned above, the tag was labeled as "Not Applicable" (Table 11). The tags in the Utilization subcategory show rather subjective or personal properties. Those tags such as resources, learning, teaching, and job imply a user's intent to use documents for particular purposes.

\subsection{Limitations}

We limited the scope of sample web documents to the common document collection of BUBL and Intute, and only if a web document was listed at both locations were tags assigned to the web document at Delicious collected and analyzed. Thus, conclusions about properties of tags in Delicious were limited to web documents selected for inclusion in subject gateways and indexed by professional indexers. In addition, analysis for content analysis of tag attributes focused on the top 20 ranked tags. A more thorough study of tagging behavior would encompass a larger number of assigned tags associated with each document.

\subsection{Conclusion}

In order to characterize the features and patterns of tags, the content analysis of tag attributes was performed based on attributes defined by the FRBR model. The findings identified the bibliographic attributes of tags beyond describing subjects or topics of a document. The findings also showed that tags have essential attributes matching those defined in FRBR. In terms of FRBR attributes, the results showed that taggers tend to mainly assign tags on attributes related to WT (Title attribute of FRBR Work entity) and WF (Form attribute of FRBR Work entity). Furthermore, in terms of specific subject areas, taggers exhibited different tagging behaviors representing distinctive features and tendencies. For three subject areas, Technology, Arts and Literature subjects, tag frequency on the FRBR WI (intended audience) attribute was relatively high, which means that taggers tend to consider audience in these subject areas. In terms of Natural sciences and Geography, the

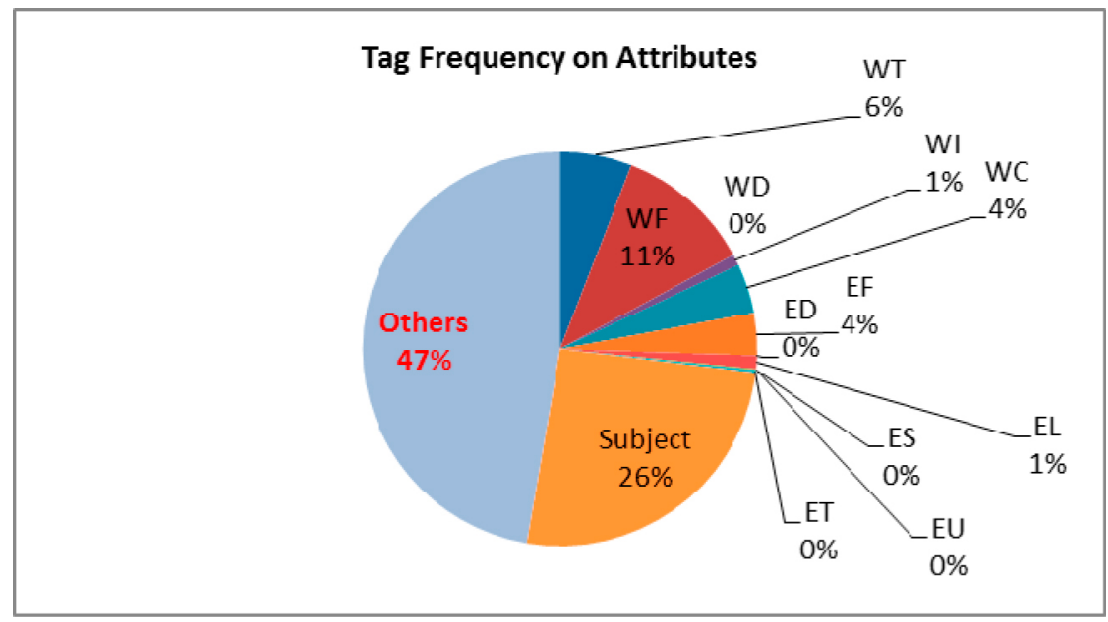

Figure 15. Other attributes of tag

\begin{tabular}{|l|l|l|}
\hline Category & Description & Tag \\
\hline Feature & $\begin{array}{l}\text { Feature is a technical feature about } \\
\text { web documents. It reflects the charac- } \\
\text { teristics of web documents. }\end{array}$ & $\begin{array}{l}\text { academic, library, conference, community, search, online, book- } \\
\text { markbar, open_acess, web2.0, library2.0, homepage, networking, } \\
\text { links, blog, tools, access, browse, portal, community, forum, pub- } \\
\text { lic-domain, wiki }\end{array}$ \\
\hline Utilization & $\begin{array}{l}\text { Utilization is about the implied pur- } \\
\text { pose of usage. }\end{array}$ & $\begin{array}{l}\text { resources, education, information, learning, e-learning, writing, } \\
\text { reading, study, teaching, job, career, tutorial }\end{array}$ \\
\hline Institution & Institution & Association, organization, foundation \\
\hline Not Applicable & $\begin{array}{l}\text { cannot be determined as any catego- } \\
\text { ries above }\end{array}$ & imported, flickr \\
\hline
\end{tabular}


tag frequency of EF (Form attribute of Expression entity) category showed relatively high proportion in comparison with those of other subject categories. This indicated that web documents in both those subject areas were characterized by taggers with a focus on specific forms. The other attributes of tags were sorted into three sub categories, Feature, Utilization, and Institution. These results have led to the conclusion that there should be an increased awareness of diverse user needs by subject in order to improve metadata in practical applications.

It should be noted that since the scope of data analysis focuses on tags describing web documents, in this research, consideration of the FRBR Manifestation entity and Item entity has been excluded. Given the characteristics of web documents in terms of "web publishing," a web document can be viewed as the "digital embodiment" of a print book or a print journal. In that case, FRBR definitions of manifestation also needed to be extended to identify different manifestations with the same content.

The results found in this research revealed that while conducting content analysis of tag attributes, there was some disagreement between two coders on two FRBR attribute categories, i.e., WF (Form of Work entity) and EF (Form of Expression entity). The examples of those tags were Books, Database, Magazine, Journal, and Encyclopedia. This disagreement on those attributes was caused by the fact that the documents, tagged with a term "Book," include the list of books or provide a feature of searching for books rather than books themselves. However, current definitions provided by FRBR do not explicitly distinguish these two attributes about web documents. To make FRBR more applicable, FRBR should be able to describe digital heterogeneous media resources which are available in various formats and multi-dimensional structures. Therefore, an important future direction for my research will involve expanding current FRBR definitions on entities and attributes for web documents in digital environments.

\section{References}

Abbott, Robert. 2009. Personal communication, May 21.

Banerjee, Mousumi, Capozzoli, Michelle, McSweeney, Laura, and Sinha, Debajyoti. 1999. Beyond kappa: a review of interrater agreement measures. Canadian journal of statistics 27: 3-23.
Bao, Shenghua, Wu, Xiaoyuan, Fei, Ben, Xue, Guirong, Su, Zhong, and Yu, Yong. 2007. Optimizing web search using social annotations. In PatelSchneider, Peter F., and Shenoy, Prashant, eds. Proceedings of the 16th international conference on World Wide Web (WWW 2007, May 8-12, 2007, Banff, Alberta, Canada). New York: ACM, pp. 501510 Available http://www2007.org/papers/paper 397.pdf.

Bakeman, Roger. 2000. Behavioral observation and coding. In Reis, Harry T., and Judd, Charles M., eds. Handbook of research methods in social and personality psychology. New York: Cambridge University Press, pp. 138-59.

Burton, Paul F., and Mackie, Morag. 1999. The use and effectiveness of the eLib subject gateways: a preliminary investigation. Program: electronic library E information systems 33: 327-37.

Choi, Yunseon. 2009. "Bringing a more accurate user's perspective into Web navigation: facet analysis of folksonomy tags." Poster presented at iConference 2009, February 8-11, 2009, Chapel Hill, North Carolina.

Choi, Yunseon. 2010a. "Enhancing access to the Web: vocabulary analysis on users' tags and professionals' index terms." Poster presented at iConference 2010, February 3-6, Champaign, Illinois.

Choi, Yunseon. 2010b. Social networking for organizing the Web: inter-indexer consistency of social tagging. Proceedings of the International Conference of Knowledge Management (October 22-23, 2010, Pittsburgh, Pennsylvania).

Choi, Yunseon. 2010c. Traditional versus emerging knowledge organization systems: consistency of subject indexing of the Web by indexers and taggers. Poster presented at the $73^{\text {rd }}$ ASIS\&T Annual Meeting: Navigating Streams in an Information Ecosystem (October 22-27, Pittsburgh, Pennsylvania).

Choy, Sheung-On, and Lui, Andrew K. 2006. Web information retrieval in collaborative tagging systems. In Nishida, Toyoaki, Shi, Zhongzhi, Visser, Ubbo, Wu, Xindong, Liu, Jiming, Wah, Benjamin, Cheung, William, and Cheung, Yiu-Ming, eds. Proceedings of the 2006 IEEE/WIC/ACM International Conference on Web Intelligence, 18-22 December, Hong Kong. Los Alamitos, Calif.: IEEE Computer Society, pp. 352-55.

Craig, Robert T. 1981. Generalization of Scott's Index of Intercoder Agreement. Public opinion quarterly 45: 260-64. 
Y. Choi. A Practical Application of FRBR for Organizing Information in Digital Environments

Crockford, Douglas. 2006. The application/json media type for JavaScript Object Notation (JSON). Available http://www.ietf.org/rfc/rfc4627.txt? number= 4627.

Dempsey, Lorcan. 2000. The subject gateway: experiences and issues based on the emergence of the Resource Discovery Network. Online information review 24: 8-23.

Dewey, Michael E. 1983. Coefficients of agreement. British journal of psychiatry 143: 487-89.

Dubois, C. P. R. 1987. Free text vs. controlled vocabulary: a reassessment. Online review 11: 243-53.

Fidel, Raya. 1991. Searchers' selection of search keys: II. Controlled vocabulary or free-text searching. Journal of the American society for information science 42: 501-14.

Golder, Scott A., and Huberman, Bernardo A. 2005. The structure of collaborative tagging systems. Available http://www.hpl.hp.com/research/idl/papers/ tags/tags.pdf.

Golder, Scott A., and Huberman, Bernardo A. 2006. Usage patterns of collaborative tagging systems. Journal of information science 32: 198-208.

Golub, Koraljka. 2006. Using controlled vocabularies in automated subject classification of textual web pages, in the context of browsing. IEEE TCDL Bulletin 2n2. Available http://www.ieee-tcdl.org/ Bulletin/v2n2/golub/golub.html.

Good, Benjamin M., and Tennis, Joseph T. 2009. Term based comparison metrics for controlled and uncontrolled indexing languages. Information research 14n1, paper 395. Available http://informationr.net/ ir/14-1/paper395.html.

Good, Benjamin M., Kawas, Edward, and Wilkinson, Mark 2007. Bridging the gap between social tagging and semantic annotation: E.D. the entity describer. Nature Precedings 945n2. Available http:// hdl.handle.net/10101/npre.2007.945

Hayes, Andrew F. 2007. Answering the call for a standard reliability measure for coding data. Communication methods and measures 1: 77-89.

Hayman, Sarah. 2007. Folksonomies and tagging: New developments in social bookmarking. In Proceedings of Ark Group Conference: Developing and Improving Classification Schemes 27-29 June, Rydges World Square, Sydney, Australia.

Heymann, Paul, Koutrika, Georgia, and Garcia-Molina, Hector. 2008. Can social bookmarking improve Web search? Proceedings of the 1st International Conference on Web Search and Data Mining, Feb. 11-12, 2008, Stanford, California. Available http://
www.wsdm2009.org/wsdm2008.org/WSDM2008papers/index.html.

Hiom, Debra. 2006. Retrospective on the RDN. Ariadne 47. Available http://www.ariadne.ac.uk/ issue $47 / \mathrm{hiom} /$.

Holsti, Ole R. 1969. Content analysis for the social sciences and bumanities. Reading, Mass.: AddisonWesley.

IFLA Study Group on the Functional Requirements for Bibliographic Records. 1998. Functional requirements for bibliographic records: final report. München: K.G. Saur.

Kipp, Margaret E.I. 2005. Complementary or discrete contexts in online indexing: a comparison of user, creator, and intermediary keywords. Canadian journal of information and library science 29: 419-36.

Kipp, Margaret E.I. 2007a. @toread and cool: tagging for time, task and emotion. Proceedings of the 8th Information Architecture Summit (LasVegas, Nevada, March 22-26, 2007). http://eprints.rclis.org/ 10445/.

Kipp, Margaret E.I. 2007b. Tagging for health information organisation and retrieval. In Tennis, Joseph T., ed. Proceedings of the North American Symposium on Knowledge Organization (NASKO), Toronto, June 14-15, 2007, pp. 63-74. Available http://hdl.handle.net/10760/14065.

Kipp, Margaret E.I., and Campbell, D. Grant. 2010. Searching with tags: do tags help users find things? Knowledge organization 37: 239-55.

Krippendorff, Klaus. 1978. Reliability of binary attribute data. Biometrics 34: 142-44.

Krippendorff, Klaus. 1980. Content analysis: an introduction to its methodology. Newbury Park, Calif.: Sage.

Krippendorff, Klaus. 1987. Association, agreement, and equity. Quality and quantity 21: 109-23.

Krippendorff, Klaus. 2004. Content analysis: an introduction to its methodology, 2nd ed. Beverly Hills, Calif.: Sage.

Krippendorff, Klaus. 2008. Testing the reliability of content analysis data: what is involved and why. In Krippendorff, Klaus, and Bock, Mary Angela, eds. The content analysis reader. Thousand Oaks, CA: Sage, pp. 350-57.

Lancaster, F. Wilfrid. 1972. Vocabulary control for information retrieval. Washington, D.C.: Information Resources Press.

Lancaster, F. Wilfrid, and Smith, Linda C. 1983. Compatibility issues affecting information systems and services. Paris: United Nations Educational, Scientific, and Cultural Organization. 
Landis, J. Richard, and Koch, Gary G. 1977. The measurement of observer agreement for categorical data. Biometrics 33: 159-74.

Lin, Xia, Beaudoin, Joan E., Bui, Yen, and Desai, Kaushal. 2006. Exploring characteristics of social classification. In Furner, Jonathan, and Tennis, Joseph T., eds. Proceedings of the 17th ASISET SIG/ CR Classification Research Workshop, Austin, Texas, 2006. Advances in Classification Research, Volume 17.

Lombard, Matthew, Snyder-Duch, Jennifer, and Bracken, Cheryl Campanella. 2005. Practical resources for assessing and reporting intercoder reliability in content analysis research projects. Available http://astro.temple.edu/ lombard/reliability/.

Macgregor, George, and McCulloch, Emma. 2006. Collaborative tagging as a knowledge organization and resource discovery tool. Library review 55: 291-300.

Makani, Joyline, and Spiteri, Louise. 2010. The dynamics of collaborative tagging: an analysis of tag vocabulary application in knowledge representation, discovery and retrieval. Journal of information and knowledge management 9: 93-103.

Maltby, Arthur. 1975. Sayers' manual of classification for librarians, 5th ed. London: Andre Deutsch.

Muddamalle, Manikya Rao. 1998. Natural language versus controlled vocabulary in information retrieval: A case study in soil mechanics. Journal of the American society for information science 49: 881-87.

Neal, Diane. 2007. Folksonomies and image tagging: seeing the future? Bulletin of the American Society for Information Science and Technology 34 no.1: 7-11.

Neal, Diane. 2010. Emotion-based tags in photographic documents: the interplay of text, image, and social influence. Canadian journal of information and library science 34: 329-53.

Neuendorf, Kimberly A. 2002. The content analysis guidebook. Thousand Oaks, Calif.: Sage.

Nicholson, Dennis, Neill, Susannah, Currier, Sarah, Will, Leonard, Gilchrist, Alan, Russell, Rosemary, and Day, Michael. 2001. HILT: High-Level Thesaurus project: final report to RSLP \& JISC.

Nowick, Elaine A., and Mering, Margaret. 2003. Comparisons between Internet users' free-text queries and controlled vocabularies: a case study in water quality. Technical services quarterly 21n2: 15-32.

Olson, Hope A., and Boll, John J. 2001. Subject analysis in online catalogs. 2nd ed. Englewood, Colorado: Libraries Unlimited.
Quintarelli, Emanuele. 2005. Folksonomies: power to the people. Paper presented at the 1st International Society for Knowledge Organization (Italy) (ISKOI), UniMIB Meeting, June 24, Milan, Italy. Available http://www.iskoi.org/doc/folksonomies. htm.

Reade, Michael, and Romaniuk, Bohdan. 2005. Acronyms, initialisms $\mathcal{E}$ abbreviations dictionary: a guide to acronyms, abbreviations, contractions, alphabetic symbols, and similar condensed appellations, 35th. ed. Detroit: Thomson/Gale.

Renear, Allen, and Choi, Yunseon. 2006. Modeling our understanding, understanding our models: the case of inheritance in FRBR. In Grove, Andrew, ed. Proceedings of the Annual Meeting of the American Society for Information Science, November 3-8, 2006, Austin, TX. Dallas, TX: Richard B. Hill.

Scott, William A. 1955. Reliability of content analysis: the case of nominal scale coding. Public opinion quarterly 17: 321-25.

Sen, Shilad, Lam, Shyong K., Rashid, Al Mamunur, Cosley, Dan, Frankowski, Dan, Osterhouse, Jeremy, Harper, F. Maxwell, and Riedl, John. 2006. Tagging, communites, vocabulary, evolution. In Hinds, Pamela, and Martin, David, eds. Proceedings of the 2006 20th anniversary conference on Computer supported cooperative work. New York: ACM, pp. 181-90. Available http://www.grouplens.org/ papers/pdf/sen-cscw2006.pdf.

Smith, Tiffany. 2007. Cataloging and you: measuring the efficacy of a folksonomy for subject analysis. In Lussky, Joan, ed. Proceedings of the 18th Workshop of the American Society for Information Science and Technology Special Interest Group/Classification Research (SIG/CR), Milwankee, Wisconsin. Retrieved from http://dlist.sir.arizona.edu/2061.

Spiteri, Louise. 2007. The structure and form of folksonomy tags: the road to the public library catalog. Information technology and libraries. 26n3: 13-25.

Taylor, Joel, and Watkinson, David. 2007. Indexing reliability for condition survey data. The conservator 30: 49-61.

Tennis, Joseph T. 2006. Social tagging and the next steps for indexing. In Furner, Jonathan, and Tennis, Joseph T., eds. Proceedings of the 17th Annual ASISET SIG/CR Classification Research Workshop: Social Classification: Panacea or Pandora? Saturday, November 4, 2006 -- Austin, TX.

Tonkin, Emma, Baptista, Ana Alice, Hooland, Seth van, Resmini, Andrea, Eva, Mendéz, and Neville, Liddy. 2007. Kinds of tags: a collaborative research study on tag usage and structure. The $6^{\text {th }}$ European 
NKOS Workshop: Networked Knowledge Organization Systems and Services at ECDL7, September 21, Budapest, Hungary.

Trant, Jennifer. 2008. Studying social tagging and folksonomy: a review and framework. Journal of digital information 10n1. Available http://journals. tdl.org/jodi/article/viewDownloadInterstitial/269/ 278.

University of Kent. 2009. Library services subject guides. Available http://www.kent.ac.uk/library/ subjects/healthinfo/subjgate.html.

Vander Wal, Thomas. 2005. "Folksonomy definition and Wikipedia." Off the top weblog. Available http://www.vanderwal.net/random/entrysel.php? blog $=1750$.

Vander Wal, Thomas. 2007. Folksonomy coinage and definition. Retrieved from http://www.vanderwal. net/folksonomy.html.

Wikipedia, the free encyclopedia. 2009. FL: Wikimedia Foundation, Inc. Available http://www.wikipedia. org.

Wimmer, Roger D., and Dominick, Joseph R. 1987. Mass media research: an introduction, $2^{\text {nd }}$ Edition. Belmont, Calif.: Wadsworth Publishing Company.

Yanbe, Yusuke, Jatowt, Adam, Nakamura, Satoshi, and Tanaka, Katsumi. 2006. Can social bookmarking enhance search in the web? In Larson, Ray R., Toms, Elaine, and Sugimoto, Shigeo, eds. JCDL '07 Proceedings of the 7th ACM/IEEE-CS joint conference on Digital libraries. New York: ACM, pp. 107-16.

Zhou, Xiaohua (Davis), Zhang, Xiaodan (Tom), and Hu, Xiaohua (Tony). 2007. The Dragon toolkit developer guide. Philadelphia: Drexel University. Available http://dragon.ischool.drexel.edu/ documentation.asp.

\section{Appendix 1. Stoplist}

\begin{tabular}{|l|l|}
\hline affordable & informative \\
awesome & personal \\
babyas & popular \\
bad & portal \\
base & post_graduate \\
befolkning & postgraduate \\
best_of_the_web & prekindergarten \\
bestoftheweb & pre-k-kindergarten \\
bookmarksbar & professional \\
bourse & professional_resource \\
by & read_later \\
ccstuff & recommend \\
cdweb & recommended_site \\
check & recommendedsite \\
collectibles & ref_source \\
convenient & search \\
cool & self-help \\
download & sharing \\
fact & staring_site \\
favorite & startingsite \\
for_student & student \\
free & stumbleupon \\
free.to.everyone & stumbleuponfavorite \\
funny & tip \\
good & to.read \\
good_info & toread \\
good_information & to_be_better_tagged \\
good_practice & toblog \\
gooddesign & tocatalog \\
good-design & todescribe \\
goodinfo & toread \\
goodpractice & useful \\
grad & useful_link \\
grad_school & useful_stuff \\
gradschool & usefulstuff \\
guide & vital_record \\
help & vitalrecord \\
how_things_work & worth \\
howto & wow \\
humor & \\
interesting & \\
\hline
\end{tabular}




\section{Appendix 2. Coding Instruction}

If you determine that a tag can be associated with a specific category of FRBR attributes, enter a number "1" in the cell. If you determine that a tag cannot be associated with any categories of FRBR attributes, leave the cell blank, and you can put your comments in the "Notes" cell, if possible. For instance, if you determine that a tag can be regarded as a "subject term", enter an "S" in the Notes cell. Otherwise, describe it, if possible, or just put a question mark "?".

\begin{tabular}{|c|c|c|c|c|c|c|c|c|c|c|c|c|c|c|}
\hline \multirow{2}{*}{$\begin{array}{l}\text { Sub- } \\
\text { ject }\end{array}$} & \multirow[t]{2}{*}{ Title } & \multirow[t]{2}{*}{ Tags } & \multicolumn{5}{|c|}{ Work } & \multicolumn{6}{|c|}{ Expression } & \multirow[t]{2}{*}{ Notes } \\
\hline & & & WT & WF & WD & WI & WC & $\mathrm{EF}$ & $\mathrm{ED}$ & EL & ES & EU & ET & \\
\hline \multirow[t]{14}{*}{001} & \multirow{14}{*}{$\begin{array}{l}\text { Institute for Psycho- } \\
\text { history: http://www. } \\
\text { psychohistory.com/ }\end{array}$} & psychology & & & & & & & & & & & & \\
\hline & & history & & & & & & & & & & & & \\
\hline & & politics & & & & & & & & & & & & \\
\hline & & $\begin{array}{l}\text { psychohis- } \\
\text { tory }\end{array}$ & & & & & & & & & & & & \\
\hline & & science & & & & & & & & & & & & \\
\hline & & culture & & & & & & & & & & & & \\
\hline & & reference & & & & & & & & & & & & \\
\hline & & world & & & & & & & & & & & & \\
\hline & & war & & & & & & & & & & & & \\
\hline & & abuse & & & & & & & & & & & & \\
\hline & & theory & & & & & & & & & & & & \\
\hline & & academic & & & & & & & & & & & & \\
\hline & & sociology & & & & & & & & & & & & \\
\hline & & parenting & & & & & & & & & & & & \\
\hline
\end{tabular}

\section{Appendix 3. A sample of coded web document based on FRBR attributes}

\begin{tabular}{|c|c|c|c|c|c|c|c|c|c|c|c|c|c|c|}
\hline \multirow[t]{2}{*}{ Subject } & \multirow[t]{2}{*}{ Title } & \multirow[t]{2}{*}{ Tags } & \multicolumn{5}{|c|}{ Work } & \multicolumn{6}{|c|}{ Expression } & \multirow{2}{*}{$\begin{array}{l}\text { Not } \\
\text { Appli- } \\
\text { cable }\end{array}$} \\
\hline & & & WT & WF & WD & WI & WC & $\mathrm{EF}$ & $\mathrm{ED}$ & EL & ES & $\mathrm{EU}$ & ET & \\
\hline \multirow{12}{*}{$\begin{array}{l}890 \text { Poetry, } \\
\text { general re- } \\
\text { sources }\end{array}$} & \multirow{12}{*}{$\begin{array}{l}\text { Modern Haiku, } \\
\text { http://www. } \\
\text { modernhaiku.org/ }\end{array}$} & haiku & 1 & & & & & & & & & & & \\
\hline & & $\begin{array}{l}\text { poetry/ } \\
\text { poems }\end{array}$ & & 1 & & & & & & & & & & \\
\hline & & japan & & & & & 1 & & & & & & & \\
\hline & & literature & & & & & & & & & & & & s \\
\hline & & magazine & & 1 & & & & & & & & & & \\
\hline & & writing & & & & & & & & & & & & $\mathrm{s}$ \\
\hline & & journal & & 1 & & & & & & & & & & \\
\hline & & words & & & & & & 1 & & & & & & \\
\hline & & review & & 1 & & & & & & & & & & \\
\hline & & world & & & & & 1 & & & & & & & \\
\hline & & $\begin{array}{l}\text { creative } \\
\text { writing }\end{array}$ & & & & & & & & & & & & s \\
\hline & & online & & & & & & & & & & & & $\mathrm{f}$ \\
\hline
\end{tabular}

S: subject, U: utilization, F: feature 